Article

\title{
Catalytic Upgrading of Bio-Oil by Reacting with Olefins and Alcohols over Solid Acids: Reaction Paths via Model Compound Studies
}

\author{
Zhijun Zhang ${ }^{1,2}$, Charles U. Pittman, Jr. ${ }^{2, *}$, Shujuan Sui ${ }^{1}$, Jianping Sun ${ }^{1}$ and \\ Qingwen Wang ${ }^{1}$ *
}

1 MOE Key Laboratory of Bio-based Material Science and Technology, Northeast Forestry University, Harbin 150040, China; E-Mails: zzj_1003@163.com (Z.Z.); suishujuan2004@yahoo.com.cn (S.S.); sunjp1977@163.com (J.S.)

2 Department of Chemistry, Mississippi State University, Mississippi State, MS 39762, USA

* Authors to whom correspondence should be addressed;

E-Mails: cpittman@chemistry.msstate.edu (C.U.P.); qwwang@nefu.edu.cn (Q.W.);

Tel.: +1-662-325-7616 (C.U.P.); Fax: +1-662-325-7611 (C.U.P.);

Tel./Fax: +86-451-82191993 (Q.W.).

Received: 5 January 2013; in revised form: 1 February 2013 / Accepted: 26 February 2013 / Published: 11 March 2013

\begin{abstract}
Catalytic refining of bio-oil by reacting with olefin/alcohol over solid acids can convert bio-oil to oxygen-containing fuels. Reactivities of groups of compounds typically present in bio-oil with 1-octene (or 1-butanol) were studied at $120^{\circ} \mathrm{C} / 3 \mathrm{~h}$ over Dowex $50 \mathrm{WX} 2$, Amberlyst15, Amberlyst36, silica sulfuric acid (SSA) and $\mathrm{Cs}_{2.5} \mathrm{H}_{0.5} \mathrm{PW}_{12} \mathrm{O}_{40}$ supported on $\mathrm{K} 10$ clay $\left(\mathrm{Cs}_{2.5} / \mathrm{K} 10,30\right.$ wt. \%). These compounds include phenol, water, acetic acid, acetaldehyde, hydroxyacetone, D-glucose and 2-hydroxymethylfuran. Mechanisms for the overall conversions were proposed. Other olefins (1,7-octadiene, cyclohexene, and 2,4,4trimethylpentene) and alcohols (iso-butanol) with different activities were also investigated. All the olefins and alcohols used were effective but produced varying product selectivities. A complex model bio-oil, synthesized by mixing all the above-stated model compounds, was refined under similar conditions to test the catalyst's activity. SSA shows the highest hydrothermal stability. $\mathrm{Cs}_{2.5} / \mathrm{K} 10$ lost most of its activity. A global reaction pathway is outlined. Simultaneous and competing esterification, etherfication, acetal formation, hydration, isomerization and other equilibria were involved. Synergistic interactions among reactants and products were determined. Acid-catalyzed olefin hydration removed water and drove the esterification and acetal formation equilibria toward ester and acetal products.
\end{abstract}


Keywords: bio-oil upgrading; model compound reactions; solid acid; reaction pathways; olefins; alcohols

\section{Introduction}

Production of renewable fuels and chemicals from lignocellulosic biomass has attracted increasing attention because of decreasing oil reserves, enhanced fuel demand worldwide, increased climate concerns, and the inherent conflict between food prices and converting edible carbohydrates to ethanol or plant oils to bio-diesel [1-4]. Bio-oils, the liquid products obtained from biomass fast pyrolysis or liquefaction, are regarded as promising renewable energy sources by the virtue of their environmentally friendly potential $[5,6]$. Nonetheless, several drawbacks of bio-oil severely limit its potential to replace or supplement high-grade transportation fuels. These include low heating values, high corrosiveness, high water content, thermal instability and immiscibility with hydrocarbon fuels etc. [7]. Thus, bio-oil has to be upgraded before using it as a fuel.

Numerous upgrading approaches to improve the bio-oil properties have been proposed, including hydrodeoxygenation, zeolite cracking, catalytic pyrolyses, steam reforming, and integrated catalytic processing such as combination of hydroprocessing and catalytic pyrolysis with zeolite catalysis [8-16]. However, these methods require temperatures from 300 to $800{ }^{\circ} \mathrm{C}$ where coke and tar easily form. This results in undesirable catalyst deactivation and reactor clogging. Hydrodeoxygenation can remove most of the oxygen present in bio-oil; but it requires high pressures and substantial amounts of hydrogen, which would negatively affect the economics of this process.

Alternatively, bio-oil can be partially refined to less hydrophilic, more combustible and more stable oxygen-containing organic fuels, where oxygen is not fully removed. Hydrogen is not employed or consumed and carbon is not lost as $\mathrm{CO}_{2}$ in this approach. Ideally, this process would retain all of the bio-oil's original caloric value in the product. An example is esterification of bio-oil's carboxylic acids with alcohols, which also converts some ketones and aldehyde content to acetals. This can improve the chemical and physical properties of bio-oil. However, water is formed in the process. Excess alcohol use and water removal during reaction is required to drive these equilibrium reactions and their separation from the upgraded products should be considered [10,12]. We recently reported a promising approach, where bio-oil was converted into oxygen-containing fuels by reacting with added olefins over solid acid catalysts at low temperatures $[17,18]$. In this approach, acid-catalyzed esterification of bio-oil carboxylic acids by alcohols formed during olefin hydration, phenol alkylation, etherification, and hydration reactions of olefins occur simultaneously to convert carboxylic acids, phenolic compounds, alcohols and water into esters, alkylated phenols, ethers and alcohols, respectively. These products are less hydrophilic and have a higher fuel value. Water is removed instead of being generated. The hydroxyl groups present in bio-oil were removed and the fuel value of the product was enhanced. By also adding a co-reagent alcohol, serious phase separation of the hydrophilic bio-oil and hydrophobic olefin was reduced. In addition, esterification and acetal formation occur and their equilibria are further driven by the removal of the product water from these reactions by its addition across the added olefins [19]. The alcohols selected, including ethanol and butanols, can be obtained 
by biomass fermentation [20,21], and they are fuels themselves. C-4 alcohols are now major industrial targets for carbohydrate or cellulose fermentation to fuels routes. If they become major commodity fuels, a portion of that production could be directed to and leveraged towards bio-oil to fuels manufacturing processes. While this future cannot be foreseen now, options should now be developed for the future.

Converting alcohols from gasoline additives to bio-oil refining reagents, which end up in the fuel, does not change their ultimate caloric contribution for fuel use. Olefin mixtures can be used. So, although olefins are consumed that may have other uses, olefins or olefin mixtures, whatever is cheaper, can be applied. For example, cheaper olefin mixtures can be obtained by pyrolysis of waste polyolefin base plastics. The total caloric content of the combined olefin and alcohol reagents remain within the refined upgraded products together with all of the original caloric content of the raw bio-oil. However, olefin/alcohol acid-catalyzed upgrading will not, and is not intended, to produce "drop in" fuels for use in gasoline or most diesel motors. Furthermore, the product is not primarily intended for subsequent feeding into refinery processes to make gasoline due to its considerable oxygen content. But the oxygenated products can be blended with petroleum fuels or biodiesel liquids and might have promise for application in low temperature/high compression diesel engines requiring low cetane number fuels someday.

In our earlier work, undesirable catalyst deactivation [18] and decomposition [17,19] occurred during these upgrading processes due to bio-oil's complex composition, especially with substantial amounts of water present. A goal of this work is to develop and apply a more highly active catalyst with good hydrothermal stability for this process. A second goal is to more fully elucidate the complex competing reaction pathways involved in the acid-catalyzed refining of bio-oil with olefins plus alcohols. Bio-oil upgrading is exceptionally complex. This is because bio-oils are composed of a wide variety of oxygenated compounds (more than 300) and its chemical composition is feedstock and pyrolysis process dependent. However, all reported bio-oils are poorly defined mixtures of carboxylic acids, alcohols, aldehydes, esters, ketones, sugars or anhydrosugars, phenolic compounds, furans, water, a few cyclic hydrocarbons and multifunctional compounds such as hydroxyacetaldehyde, hydroxyacetic acid, hydroxyacetone, etc. [7]. Model compounds and their mixtures are often first employed to study the reaction steps involved in bio-oil upgrading processes [10,12,13]. For this work, we have selected phenol, water, acetic acid, acetaldehyde hydroxyacetone, D-glucose and 2-hydroxymethylfuran as typical bio-oil components and mixed them as a synthetic bio-oil. This composition contains a better representation of the types of compounds involved in the many reactions competing during refining and has allowed a more complete understanding of the reaction paths. Solid acid catalyzed reactions of 1-octene/1-butanol with this synthetic bio-oil were investigated in the liquid phase, respectively, over Dowex50WX2 (DX2), Amberlyst15 (A15), Amberlyst36 (A36), $\mathrm{Cs}_{2.5} \mathrm{H}_{0.5} \mathrm{PW}_{12} \mathrm{O}_{40}$ (an insoluble acidic heteropoly acid salt) and silica sulfuric acid (SSA) catalysts. All of these catalysts are reported water-tolerant strong acids. A short preliminary communication in Bioresource Technology [22] on this effort has appeared. The full study is reported here.

SSA is a superior proton source compared with many acidic solid supports, such as styrene/divinylbenzene sulfonic acid resins and Nafion-H [23]. SSA exhibited good activity and stability in preliminary catalytic upgrading of model bio-oils by simultaneous reactions with 1-butanol and 1-octene [22]. Reaction pathways were proposed, but, more systematic research was needed to 
examine upgrading feasibility and elucidate the complicated reaction mechanism. Thus, various olefins and alcohols are investigated in reactions with phenol/water (1:1) mixtures in this paper. Also, reactions of 1-octene with phenol, phenol/water, phenol/water/acetic acid, phenol/water/1-butanol, phenol/water/2-hydroxymethylfuran, phenol/water/D-glucose, phenol/water/hydroxyacetone and phenol/water/acetic acid/1-butanol are reported here. Herein, we present a more comprehensive reaction pathway and demonstrate coking/catalyst poisoning caused by hydroxyacetone, 2-hydroxy-methylfuran and D-glucose.

\section{Results and Discussion}

\subsection{Catalyst Characterization}

The silica sulfuric acid ( $\mathrm{SSA}), \mathrm{SiO}_{2}-\mathrm{OSO}_{3} \mathrm{H}$, prepared by reacting silica gel with chlorosufonic acid in dichloromethane was obtained as a white solid in $98 \%$ yield. Table 1 summarizes the physical properties (surface area, pore size, pore volume and acidity amount) as well as chemical compositions of SSA and other four catalysts. The specific surface area was calculated using the BET equation. The total pore volume was determined at $77 \mathrm{~K}$ for $300 \mathrm{~min}$ and also the average pore diameter were was calculated using the Barrett-Joyner-Halenda (BJH) method. The amount of $\mathrm{H}^{+}$was calculated by titration of catalyst samples in water with standard sodium hydroxide $(0.495 \mathrm{M})$. These results show that SSA have a good specific surface area than the three ion exchange resins and high pore volume than $\mathrm{Cs}_{2.5} / \mathrm{K} 10$. This might be a reason for high catalytic performance of the SSA catalyst in the experimental conditions. Negligible decreases in pore volume, surface area and pore diameter of once used SSA catalyst (Table 1) displayed its good reusability.

Table 1. Characteristics of catalysts ${ }^{\text {a }}$.

\begin{tabular}{|c|c|c|c|c|c|}
\hline Catalysts & $\mathrm{Cs}_{2.5} / \mathrm{K} 10$ & Amberlyst36 & Amberlyst15 & Dowex50X2 & SSA \\
\hline Description & $\begin{array}{l}\mathrm{Cs}_{2.5} \mathrm{H}_{0.5} \mathrm{PW}_{12} \mathrm{O}_{40} \\
\text { supported on clay }\end{array}$ & $\begin{array}{l}\text { Macroreticular } \\
\text { resin }\end{array}$ & $\begin{array}{c}\text { Macroreticular } \\
\text { resin }\end{array}$ & $\begin{array}{l}\text { Microreticular } \\
\text { resin }\end{array}$ & $\begin{array}{c}\text { Silica sulfuric } \\
\text { acid }\end{array}$ \\
\hline $\begin{array}{c}\text { Chemical } \\
\text { composition }\end{array}$ & $\begin{array}{c}\mathrm{Cs}_{2.5} \mathrm{H}_{0.5} \mathrm{PW}_{12} \mathrm{O}_{40} \\
\text { /aluminosilicate } \\
\text { (lamellar), } 30 \%\end{array}$ & $\begin{array}{c}\text { Functionalized } \\
\text { copolymers } \\
\text { (styrene + DVB) }\end{array}$ & $\begin{array}{c}\text { Copolymer } \\
\text { (styrene }+20 \% \\
\text { DVB })\end{array}$ & $\begin{array}{c}\text { Copolymer } \\
\text { (styrene }+2 \% \\
\text { DVB) }\end{array}$ & $\mathrm{SiO}_{2}-\mathrm{OSO}_{3} \mathrm{H}$ \\
\hline Acidity type & Brönsted + Lewis & Brönsted & Brönsted & Brönsted & Brönsted \\
\hline $\begin{array}{c}\text { Acidity amount } \\
\left(\mathrm{meq}^{\left.-\mathrm{g}^{-1}\right)}\right.\end{array}$ & 0.17 & 5.4 & 4.7 & 4.3 & $2.9(2.7)$ \\
\hline $\begin{array}{l}\text { BET surface } \\
\text { area }\left(\mathrm{m}^{2} \cdot \mathrm{g}^{-1}\right)\end{array}$ & 181 & 35 & 51 & Gel (swells) & $308(302)$ \\
\hline $\begin{array}{l}\text { Average pore } \\
\text { diameter (nm) }\end{array}$ & 6.0 & 24 & $40-80$ & NA & $2.1(2.0)$ \\
\hline $\begin{array}{l}\text { pore volume } \\
\left(\mathrm{cm}^{3} \cdot \mathrm{g}^{-1}\right)\end{array}$ & 0.29 & 0.20 & 0.40 & NA & $0.509(0.498)$ \\
\hline
\end{tabular}

${ }^{a}$ All the characteristics of the three resin catalysts were provided by the manufacturer; NA: not available; The corresponding characteristics of once used SSA (washed 3 times with acetone, dried in an oven at $105{ }^{\circ} \mathrm{C}$ for $30 \mathrm{~min}$ prior to test) are shown in parentheses as bold italic type. 
Table 2 summarizes its typical IR absorptions and their assignments. The strong broad absorption bands from 1000 to $1100 \mathrm{~cm}^{-1}$ correspond to Si-O-Si bridge stretching vibrations (1097 and $1065 \mathrm{~cm}^{-1}$ ) in silica [23]. The peak at $c a .971 \mathrm{~cm}^{-1}$ is associated with Si-OH stretching vibrations in silica. Bands appearing at $c a .852$ and $886 \mathrm{~cm}^{-1}$ were assigned to the symmetrical and asymmetrical S-O stretching, respectively [24]. The peak at $c a .1178 \mathrm{~cm}^{-1}$ is the asymmetric $\mathrm{S}=\mathrm{O}$ stretching vibration, while $\mathrm{S}=\mathrm{O}$ symmetrical stretching vibrations lies at $1010-1080 \mathrm{~cm}^{-1}$, overlapped by Si-O stretching bands [24]. The strong broad absorption at about $3200-3500 \mathrm{~cm}^{-1}$ is due to hydrogen bonded $-\mathrm{OH}$ in $\mathrm{SiO}_{2}-\mathrm{OSO}_{3} \mathrm{H}$. Characteristic IR absorptions of $\mathrm{Cs}_{2.5} / \mathrm{K} 10$ are also summarized in Table 2. The IR bands at $c a .1075 \mathrm{~cm}^{-1}, 1032 \mathrm{~cm}^{-1}$ and $982 \mathrm{~cm}^{-1}$ were due to $\mathrm{P}-\mathrm{O}$ in the central tetrahedron, K10 clay and terminal $\mathrm{W}=\mathrm{O}$, respectively. The peaks at $c a .886$ and $790 \mathrm{~cm}^{-1}$ (asymmetric $\mathrm{W}-\mathrm{O}-\mathrm{W}$ vibrations) are associated with the Keggin polyanion [18].

Table 2. Characteristic IR absorptions for SSA and $\mathrm{Cs}_{2.5} / \mathrm{K} 10$ catalysts [22].

\begin{tabular}{cc|cc}
\hline \multicolumn{2}{c|}{ SSA } & \multicolumn{2}{c}{$\mathbf{C s}_{\mathbf{2 . 5}} / \mathbf{K 1 0}$} \\
\hline Absorption $\left(\mathbf{c m}^{-\mathbf{1}}\right)$ & Assignment & Absorption $\left.\mathbf{( c m}^{-\mathbf{1}}\right)$ & Assignment \\
\hline $3200 \sim 3500$ & hydrogen bonded $-\mathrm{OH}$ & 1075 & P-O stretching \\
1178 & $\mathrm{~S}=\mathrm{O}$ symmetrical stretching & 1032 & Si-O in K10 clay \\
$1000 \sim 1100$ & Si-O-Si bridge stretching & 982 & terminal W=O \\
971 & Si-OH stretching & 886,790 & W-O-W vibrations \\
852,886 & S-O stretching & & \\
\hline
\end{tabular}

\subsection{Catalytic Activity}

Phenol, water, acetic acid, acetaldehyde, hydroxyacetone, D-glucose and 2-hydroxymethylfuran were mixed together and used as a model bio-oil to react with 1-octene/1-butanol at $120^{\circ} \mathrm{C}$ for $3 \mathrm{~h}$ over each of the five catalysts: $\mathrm{Cs}_{2.5} / \mathrm{K} 10, \mathrm{~A} 15, \mathrm{~A} 36, \mathrm{DX} 2$ and SSA. Table 3 shows the 1-octene, 1-butanol and phenol conversions as well as the 1 -octene isomerization and $O$-alkylation selectivities of these reactions [22]. 1-Octene conversions differed significantly over these catalysts and followed the order: SSA $(\approx 60 \%)>$ DX2 $(40-50 \%)>$ A15 $(27 \%)>$ A36 $(14 \%)>\mathrm{Cs}_{2.5} / \mathrm{K} 10(10 \%)$. Similar differences occurred for both phenol conversion and 1-octene isomerization. The phenol conversion was higher with SSA (64.1\%) verses DX2 (37.3\%), A15 (27.6\%), A36 (6.1\%) and $\mathrm{Cs}_{2.5} / \mathrm{K} 10$ (1.2\%). The 1-octene isomerization activities of these five catalysts are $87.9 \%$ (SSA), 55.5\% (DX2), 54.1\% (A15), 13.5\% (A36) and $1.9 \%\left(\mathrm{Cs}_{2.5} / \mathrm{K} 10\right)$. These follow the same order and show the higher activity of the SSA catalyst. Higher phenol conversion was accompanied by higher 1-octene isomerization activity and higher 1-octene conversions. SSA is the most active catalyst. This is because it is a stronger acid than the three resin sulfonic acids. Compared with the resin sulfonic acids ( $\mathrm{P}_{-} \mathrm{C}_{6} \mathrm{H}_{4}-\mathrm{SO}_{3} \mathrm{H}$ ), where the $\mathrm{S}$ atom has $3 \mathrm{O}$ atoms attached, the $\mathrm{S}$ atom in $\mathrm{SSA}\left(\mathrm{SiO}_{2}-\mathrm{OSO}_{3} \mathrm{H}\right.$ ) has $4 \mathrm{O}$ atoms attached. This causes the weaker basicity of $-\mathrm{O}-\mathrm{SO}_{3}^{\ominus}$ verses that of $\mathrm{Ph}-\mathrm{SO}_{3}^{\ominus}$. Thus, SSA is the strongest acid. The stronger the acid, the more 1-octene protonation is favored. Hence, more octyl cations are generated. With the increase in octyl cation concentration, both phenol alkylation (phenolic oxygen attack on the carbocation) and 1-octene isomerization reaction (loss of proton from the carbocation) would speed up 
accompanied with faster consumption of 1-octene. This is consistent with higher phenol conversion and both 1-octene isomerization activity and conversion to other products with SSA.

Table 3. 1-Octene, 1-butanol and phenol conversions, 1-octene isomerizations and $O$-alkylation selectivities in reactions of a model bio-oil with 1-octene/1-butanol over $\mathrm{Cs}_{2.5} / \mathrm{K} 10, \mathrm{~A} 36, \mathrm{~A} 15, \mathrm{DX} 2$ and SSA at $120^{\circ} \mathrm{C}$ for $3 \mathrm{~h}^{\mathrm{a}}$.

\begin{tabular}{cccccc}
\hline Catalyst & $\begin{array}{c}\text { 1-Octene conversion } \\
\mathbf{( \% )}^{\mathbf{b}}\end{array}$ & $\begin{array}{c}\text { Phenol conversion } \\
\mathbf{( \% )}^{\mathbf{c}}\end{array}$ & $\begin{array}{c}\text { 1-Octene isomerization } \\
\mathbf{( \% )}^{\mathbf{d}}\end{array}$ & $\begin{array}{c}\text { 1-Butanol } \\
\text { conversion (\%) }^{\mathbf{e}}\end{array}$ & $\begin{array}{c}\boldsymbol{O} \text {-alkylates } \\
\text { selectivity (\%) }\end{array}$ \\
\hline $\mathrm{Cs}_{2.5} / \mathrm{K} 10$ & 10.1 & 1.2 & 1.9 & 68.2 & 42.0 \\
$\mathrm{~A} 36$ & 14.0 & 6.1 & 13.5 & 94.3 & 67.7 \\
$\mathrm{~A} 15$ & 27.1 & 27.6 & 54.1 & 97.4 & 73.7 \\
$\mathrm{DX} 2$ & 43.1 & 37.3 & 55.5 & 90.5 & 73.9 \\
$\mathrm{SSA}$ & 60.1 & 64.1 & 87.9 & 97.4 & 64.1 \\
\hline
\end{tabular}

a Material ratio: 1-octene: 1-butanol: phenol: water: acetic acid: acetaldehyde: hydroxyacetone: D-glucose: 2-hydroxymethylfuran $(\mathrm{g})=1.35: 0.15: 0.94: 0.15: 0.15: 0.12: 0.12: 0.15: 0.15$, catalyst: $0.15 \mathrm{~g} ;{ }^{\mathrm{b}}$ 1-Octene conversion $=100 \% \times(1-$ GC area $\%$ of unreacted octenes versus the sum of the GC area $\%$ of alkylated phenols, octanols, dioctyl ethers, oligomers and octyl acetates); ${ }^{\mathrm{c}}$ Phenol conversions $=100 \% \times \mathrm{GC}$ area $\%$ of phenol alkylates versus the sum of the GC area\% of unreacted phenol and phenol alkylates; ${ }^{d}$ Percent of 1 -octene isomerization $=100 \% \times$ (1- GC area\% of 1-octene versus the sum of the GC area\% of 1-octene and 1-octene isomers); ${ }^{\mathrm{e}} 1$-Butanol conversion $=100 \% \times(1-\mathrm{GC}$ area $\%$ of unreacted 1-butanol versus the sum of the GC area $\%$ of butyl acetate, dibutyl ether, 1,1-dibutoxyethane and butyl levulinate); ${ }^{\mathrm{f}} \mathrm{O}$-Alkylates selectivity $=100 \% \times \mathrm{GC}$ area $\%$ of $O$-alkylates versus the sum of the GC area\% of all phenol alkylates.

Stronger acids also promote both esterification and acetal formation rates. This can be observed from the higher 1-butanol conversion (97.4\%) with SSA catalyst. Except for the modest 1-butanol conversion (68\%) formed over $\mathrm{Cs}_{2.5} / \mathrm{K} 10$, 1-butanol conversions with the three resin sulfonic acids catalysts all exceeded 90\%. Carboxylic acid esterifications and aldehyde/ketone acetal formation with 1-butanol are reversible or equilibrium reactions. The desirable forward reaction products like esters and acetals were produced accompanied by formation of water. That water and the original water present in bio-oil would inhibit the forward reactions, limiting further formation of more esters and acetals. Water removal by acid catalyzed hydration of 1-octene helped to shift these equilibria forming esters and acetals toward completion.

Phenol alkylates ( $C$ - and $O$-) are desired because of their high octane number and high heating values [15]. The $O$-alkylated products are especially desirable because the acidic phenolic hydroxyl group is converted to an ether lowering product acidity and decreasing hydrophilicity. Moreover, $O$-alkylated phenol ethers are readily combusted. Except for $\mathrm{Cs}_{2.5} / \mathrm{K} 10$, all the catalysts gave high $O$-alkylation selectivity $(>60 \%)$. Compared with the three resin sulfonic acids, SSA gives more $C$-alkylates because that stronger acid promotes conversion of $O$-alkylates into the thermodynamic phenol $C$-alkylates by enhancing $O$-alkylate protonation.

SSA exhibited a higher water-tolerance than other catalysts based on the model systems shown in Table 3. Desulfonation of the three resin sulfonic acids catalyst occurred progressively at $120{ }^{\circ} \mathrm{C}$ over time, leading to partial deactivation of these catalysts. $\mathrm{Cs}_{2.5} / \mathrm{K} 10$ lost almost all catalytic activity. 


\subsection{Reactivities of Model Bio-Oil Components}

In order to prove the feasibility of this upgrading process, more clearly outline the complicated reaction mechanism and probe the causes for catalyst deactivation, additional model reactions were investigated. Figure 1 shows the phenol conversions of phenol/1-octene reactions at $120{ }^{\circ} \mathrm{C}$ for $3 \mathrm{~h}$ over all five catalysts both with and without water present. All the catalysts exhibit high activities in neat phenol/1-octene reactions based on the high phenol conversions $(>80 \%)$. Water significantly lowered the phenol conversions of phenol/1-octene reactions over DX2 (42.1\%), A36 (38.3\%), A15 (15.8\%) and $\mathrm{Cs}_{2.5} / \mathrm{K} 10$ (19.9\%). However, a good phenol conversion (74.5\%) was still obtained over SSA. This further illustrated the high activity of SSA under hydrothermal conditions.

Figure 1. Comparison of phenol conversions by 1-octene with and without water present at $120{ }^{\circ} \mathrm{C}$ over Amberlyst15, $\mathrm{Cs}_{2.5} / \mathrm{K} 10$, Amberlyst36, Dowex50WX2 and SSA (catalyst, $0.15 \mathrm{~g}$; time: $3 \mathrm{~h}$; 1-octene: phenol: water $(\mathrm{mmol})=10: 10: 10)$.

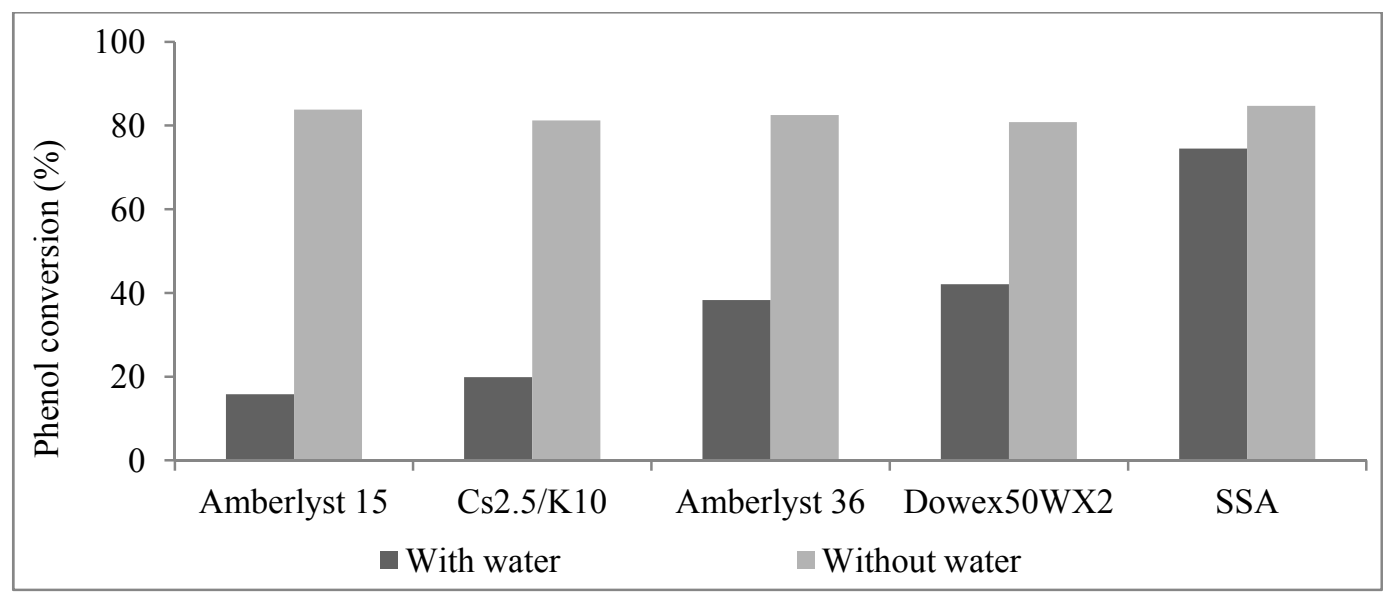

Phenolic compounds are present in bio-oils, primarily derived from lignin species. These acidic phenolic fractions are prone to oligomerization reactions with other bio-oil components [25]. Friedel-Crafts-type alkylations of phenol with 1-octene over solid catalysts leads to a mixture of $O$ - and $C$-alkylated phenols (Table 4). Isomeric octyl phenyl ethers ( $O$-alkylates) and octyl phenols (ortho/para-C-alkylates) were formed (Scheme 1), indicating that the 2-octyl carbocation undergoes 1, 2-hydride shifts to generate the 3 - and 4-octyl cations in competition with $O$ - and $C$-alkylation. $O$-Alkylation is faster than $C$-alkylation but $O$-alkylation is reversible and the initially generated $O$-alkylated products can be increasingly converted to $C$-alkylated (thermodynamic) products as a function of reaction conditions. All catalyst used gave high phenol conversions (Figure 1).

Water is the most abundant compound in raw bio-oil. It is difficult to remove due to its miscibility with hydrophilic thermolysis products present from cellulose and hemicellulose [5,6]. Phenol conversions from the reactions of 1-octene with water/phenol over solid acid catalysts were summarized in Figure 1. The lower phenol consumption with all catalysts when water was present is most likely due to water solvation of the sulfonic acid sites which lowers the Bronsted acidity or to mass transport effects due to phase separation. The sulfonic acid resins showed higher phenol conversions than $\mathrm{Cs}_{2.5} / \mathrm{K} 10$. This could be due to swelling of resins. This swelling allows a distribution of all reactants to access a larger fraction of the internal acid sites of this macroreticular resin. 
However, partial Amberlyst15 decomposition occurred. Product distributions of these reactions are shown in Table 5. Obviously, competition between water and phenol for 1-octene occurred because 1-octanol and its isomers were formed by water uptake. Intermolecular reaction of these octanols further formed ethers (Scheme 2). Meanwhile, the significant increase in the concentration of octanols with increasing water concentration affirmed the water consumption by olefin hydration [18]. Olefin acid-catalyzed hydration removes water. This is the key reason for the success of this upgrading process.

Table 4. Product distributions of 1-octene reaction with neat phenol over different catalysts at $120^{\circ} \mathrm{C}^{\text {a }}$.

\begin{tabular}{cccc}
\hline \multirow{2}{*}{ Catalyst } & \multicolumn{3}{c}{ Selectivity (\%) } \\
\cline { 2 - 4 } & $\boldsymbol{O}$-alkylates & $\boldsymbol{C}$-alkylates & Di- $\boldsymbol{C}$-alkylates \\
\hline Amberlyst 15 & 5.5 & 86.0 & 8.5 \\
Cs $_{2.5} / \mathrm{K} 10$ & 3.2 & 65.9 & 30.9 \\
Amberlyst 36 & 8.0 & 86.3 & 5.7 \\
Dowex50WX2 & 33.5 & 63.2 & 3.3 \\
SSA & 37.2 & 34.4 & 28.4 \\
\hline
\end{tabular}

${ }^{a}$ Reaction conditions: (solid catalyst, 0.15 g; time: 3 h; 1-octene: phenol $(\mathrm{mmol})=10: 10$.

Scheme 1. Acid-catalyzed reactions of phenol as a model phenolic compound with 1-octene.

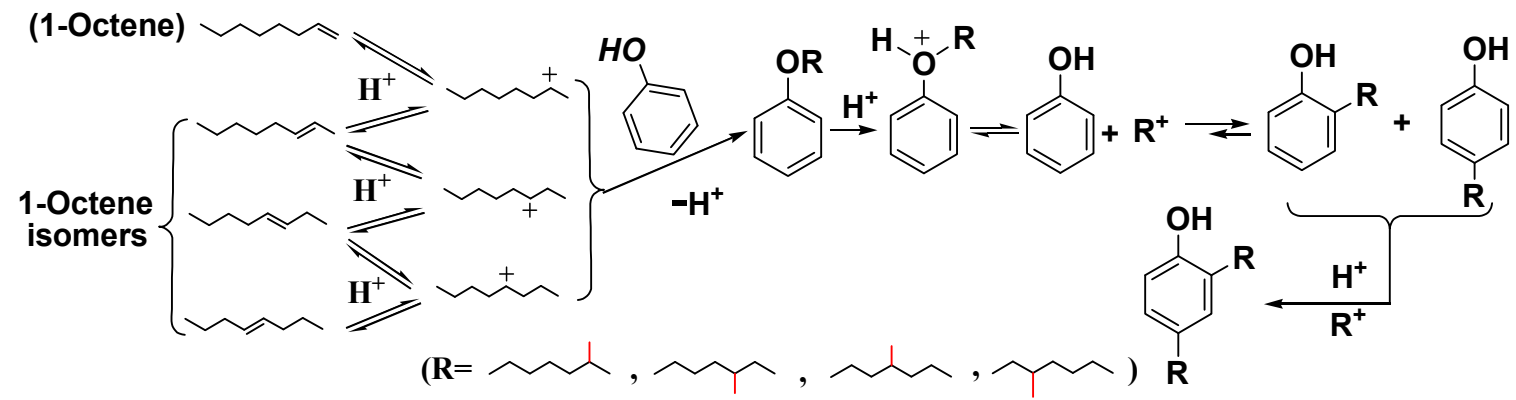

Table 5. Product distributions from 1 -octene reactions in phenol/water at $120^{\circ} \mathrm{C}$ a

\begin{tabular}{|c|c|c|c|c|c|}
\hline \multirow{2}{*}{ Catalyst } & \multicolumn{3}{|c|}{ Selectivity (\%) } & \multicolumn{2}{|c|}{${ }^{b}$ Yield (\%) } \\
\hline & $O$-alkylates & $C$-alkylates & Di- $C$-alkylates & Octanols & Dioctyl ethers \\
\hline Amberlyst 15 & 82.5 & 16.0 & 1.5 & 5.4 & 0.2 \\
\hline $\mathrm{Cs}_{2.5} / \mathrm{K} 10$ & 75.9 & 20.8 & 3.3 & 6.7 & 0.4 \\
\hline Amberlyst 36 & 73.7 & 25.0 & 1.4 & 0.7 & 0.2 \\
\hline Dowex50WX2 & 84.5 & 12.5 & 3.0 & 4.7 & 1.7 \\
\hline SSA & 75.1 & 19.5 & 5.4 & 3.4 & 1.7 \\
\hline
\end{tabular}

${ }^{\mathrm{a}}$ Reaction conditions: (solid catalyst, $0.15 \mathrm{~g}$; time: $3 \mathrm{~h}$; 1-octene: phenol: water (mmol) $=10: 10: 10$.

${ }^{\mathrm{b}} \mathrm{GC}$ area\% of involved compounds versus the sum of the GC area\% of all products that remained after the reaction.

Carboxylic acids, like acetic and propanoic acids, make bio-oil corrosive, especially at an elevated temperature [7]. 1-Octene was reacted with phenol/water/acetic acid solutions and their phenol conversions and octyl acetates yields were shown in Table 6. Along with the 1-octene hydration and phenol alkylation, simultaneous conversion of acetic acid to octyl acetates occurred by addition across 
1-octene (Scheme 3), generating three groups of improved fuel components in one operation without water generation. Trace amount of phenyl acetate were formed. The phenyl acetate yield decreased with increasing temperatures from 60 to $100{ }^{\circ} \mathrm{C}$ [17]. Both SSA and DX2 show higher catalytic activity than other three catalysts based on related phenol conversions and octyl acetates yields.

Scheme 2. Acid-catalyzed reactions of water with 1-octene.

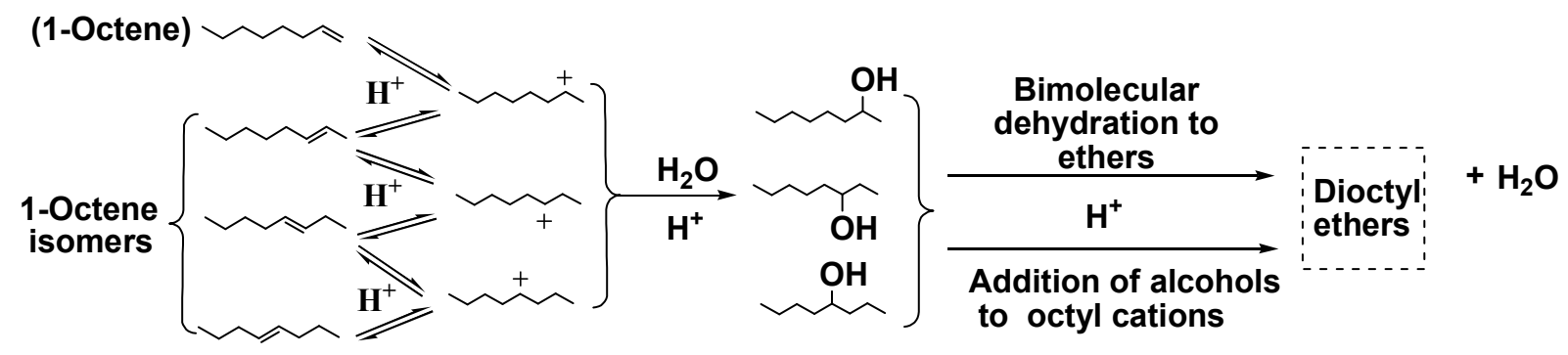

Table 6. Phenol conversions and octyl acetates yield of 1-octene reactions with phenol/water/acetic acid over different catalysts at $120^{\circ} \mathrm{C}$.

\begin{tabular}{lcc}
\hline \multicolumn{1}{c}{ Catalyst } & Phenol Conversion (\%) & ${ }^{\mathbf{b}}$ Yield (\%) Octyl acetates \\
\hline Amberlyst 15 & 5.6 & 0.6 \\
$\mathrm{Cs}_{2.5} / \mathrm{K} 10$ & 2.3 & 0.4 \\
Amberlyst 36 & 6.5 & 1.0 \\
Dowex50WX2 & 63.1 & 4.3 \\
SSA & 67.2 & 9.4 \\
\hline
\end{tabular}

${ }^{\mathrm{a}}$ Reaction conditions: (solid catalyst, $0.15 \mathrm{~g}$; time: 3 h; 1-octene: phenol: water: acetic acid (mmol) = 10:10:10:3.0;

${ }^{\mathrm{b}} \mathrm{GC}$ area $\%$ of involved compounds versus the sum of the $\mathrm{GC}$ area $\%$ of all products remained after the reaction.

Scheme 3. Acid-catalyzed reactions of acetic acid as a model carboxylic acid with 1-octene.

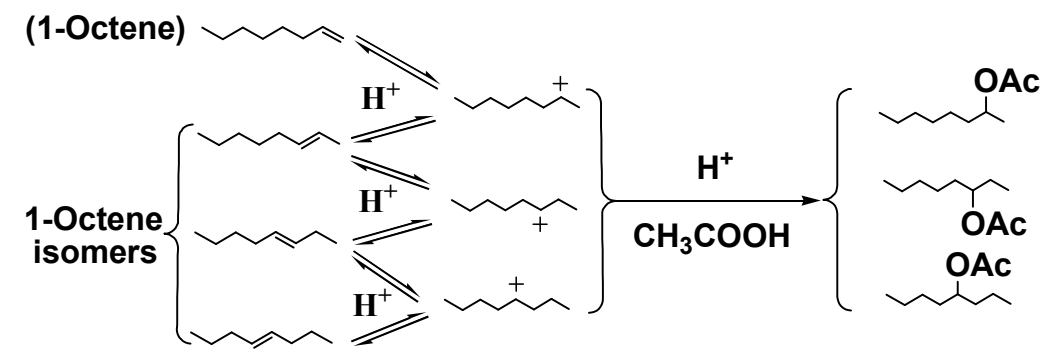

Bio-oil contains a large number of primary and secondary aliphatic hydroxyl groups from cellulose and hemicellulose pyrolysis. Table 7 provides the phenol conversions and butyl octyl ethers yields of 1-octene reactions with phenol/water/1-butanol mixtures over Dowex50WX2, SSA, Amberlyst15 and $\mathrm{Cs}_{2.5} / \mathrm{K} 10$, respectively. Except for the reactions mentioned above, butyl octyl ethers were generated by either 1-butanol etherification with octanols or 1-butanol addition across octenes (Scheme 4). SSA gave the highest phenol conversion (69.2\%), illustrating it had the highest catalytic activity. $\mathrm{Cs}_{2.5} / \mathrm{K} 10$, which gave a phenol conversion of only $6.9 \%$, lost almost all its activity during the reaction.

Multifunctional compounds such as hydroxyacetone or hydroxyethanal in bio-oil can oligomerize and polymerize. Aldol condensation reactions accelerate bio-oil aging [7]. Table 8 summarizes the effect of the presence of hydroxyacetone upon 1-octene reactions with phenol/water over $\mathrm{Cs}_{2.5} / \mathrm{K} 10$ 
and SSA catalysts. A good phenol conversion (64.0\%) was obtained over SSA. $\mathrm{Cs}_{2.5} / \mathrm{K} 10$ was deactivated by hydroxyacetone based on the greatly reduced phenol conversion (2.2\%). No hydroxyacetone was detected after reaction. However, small amounts of 3-methyl-2-hydroxycyclopent2 -enone were detected. To further study this issue, neat 1 -hydroxyacetone was heated at $100{ }^{\circ} \mathrm{C}$ for $1 \mathrm{~h}$ over $30 \% \mathrm{Cs}_{2.5} / \mathrm{K} 10$ and the products were identified by GC-MS (Table 9) [22]. Propionic acid (43.7\%), hydroxyacetone dimers $(24.8 \%)$ and 2-hydroxy-3-methylcyclopent-2-enone $(9.7 \%)$ formed, together with about $1.8 \%$ of an unknown species. Three carbon $\alpha$-hydroxycarbonyl species such as 1-hydroxyacetone (acetol) can undergo enolization and dimerization to yield the structures illustrated in Scheme 5. The keto form of 1-hydroxyacetone exists in equilibrium with its enol, enediol and aldehydo forms. In both neat and concentrated solutions, 1-hydroxyacetone can dimerize generating the cyclic structures (a) and (b). Decomposition of (b) produces propionic acid. Meanwhile, intermolecular aldol condensation reactions of 1-hydroxyacetone and subsequent serial of dehydration reactions occurred generating 3-methyl-2-hydroxycyclopent-2-enone (c) and its isomers. As a consequence of dimerization and aldol condensation, the 1-hydroxyacetone monomers are expected to diminish with time during upgrading.

Table 7. Yields of butyl octyl ethers and phenol conversions in acid-catalyzed 1-octene reactions with phenol/water/1-butanol over different catalysts at $120{ }^{\circ} \mathrm{C}$ a

\begin{tabular}{ccc}
\hline Catalyst & $\begin{array}{c}\text { Phenol } \\
\text { Conversion (\%) }\end{array}$ & $\begin{array}{c}\text { b Yield (\%) } \\
\text { Butyl octyl ethers }\end{array}$ \\
\hline Amberlyst 15 & 40.7 & 0.17 \\
Cs $_{2.5}$ K10 & 6.9 & nd \\
Dowex50WX2 & 40.6 & 0.69 \\
SSA & 69.2 & 0.24 \\
\hline
\end{tabular}

${ }^{\mathrm{a}}$ Reaction conditions: (solid catalyst, $0.15 \mathrm{~g}$; time: 3 h; 1-octene: phenol: water: 1-butanol (mmol) $=10: 10: 11.6: 3.4$;

${ }^{\mathrm{b}} \mathrm{GC}$ area $\%$ of involved compounds versus the sum of the $\mathrm{GC}$ area $\%$ of all products remained after the reaction.

Scheme 4. Acid-catalyzed reactions of 1-butanol as a model alcohol with 1-octene.

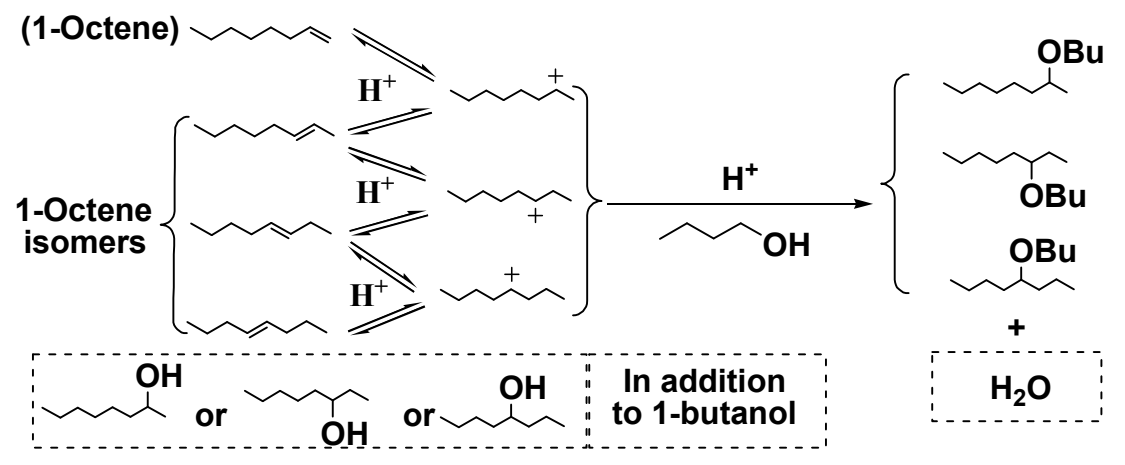

Furan derivatives such as 2-hydroxymethylfuran and hydroxymethylfurfural present in bio-oil can polymerize easily and give tar in the presence of acid [26]. Table 8 shows the effect of 2-hydroxymethylfuran addition on the 1-octene reaction with phenol/water over $\mathrm{Cs}_{2.5} / \mathrm{K} 10$ and SSA catalysts. SSA shows a good catalytic activity giving a phenol conversion of $64.7 \%$. However, the $\mathrm{Cs}_{2.5} / \mathrm{K} 10$ surfaces coked seriously, which greatly decreased its catalytic activity and reduced phenol conversion (4.5\%). Polymerization of 2-hydroxymethylfuran occurred under acidic conditions forming 
coke or tar on the catalysts [27]. This has been further confirmed by the reaction products identified from GC-MS analysis (Table 8) of the reaction where neat 2-hydroxymethylfuran $(2 \mathrm{~g})$ was heated at $100{ }^{\circ} \mathrm{C}$ for or $1 \mathrm{~h}$ over $30 \% \mathrm{Cs}_{2.5} / \mathrm{K} 10$. In addition to the unreacted 2-hydroxymethylfuran, difurfuryl ether (9.4\%), 5-furfuryl-furfuryl alcohol (4.9\%) and difuran-2-ylmethane (4.8\%), together with about $2.6 \%$ other compounds were detected in the products [22]. Rapid polymerization of 2-hydroxymethylfuran occurred at $120{ }^{\circ} \mathrm{C}$ via acid-catalyzed electrophilic condensation with the accompanying loss of formaldehyde [18], generating difurfuryl ether, 5-furfuryl-furfuryl alcohol, difuran-2-ylmethane, etc. (Scheme 6).

Table 8. Phenol conversions and yields of new products derived from the added reagent (2-hydroxymethylfuran or hydroxyacetone or D-glucose) in 1-octene reactions with water/phenol ${ }^{\mathrm{a}}$.

\begin{tabular}{cccc}
\hline Added Reagent & Catalyst & Phenol conversion (\%) & d Products yield (\%) \\
\hline Hydroxyacetone & $\mathrm{SSA}$ & 64.0 & Methyl cyclopentenolone $(0.12)$ \\
& $\mathrm{Cs}_{2.5} / \mathrm{K} 10$ & 2.2 & Methyl cyclopentenolone, (0.21) \\
\hline 2-Hydroxymethylfuran & $\mathrm{SSA}$ & 65.0 & $\mathrm{UN}^{\mathrm{b}}(0.18)$ \\
& $\mathrm{Cs}_{2.5} / \mathrm{K} 10$ & 4.5 & $\mathrm{UN}^{\mathrm{b}}(0.87)$ \\
\hline D-glucose & $\mathrm{SSA}$ & 64.7 & Anhydrosugar $^{\mathrm{c}}(0.14)$ \\
& $\mathrm{Cs}_{2.5} / \mathrm{K} 10$ & 3.5 & Anhydrosugar $^{\mathrm{c}}(0.20)$ \\
& $\mathrm{A} 15$ & 40.5 & octyl formates, 0.28 \\
& $\mathrm{DX} 2$ & 41.3 & octyl formates, 0.36 \\
\hline
\end{tabular}

${ }^{\mathrm{a}}$ Reaction conditions: $\left(120^{\circ} \mathrm{C}, 3 \mathrm{~h}\right.$, catalyst, $0.15 \mathrm{~g}$; 1-octene $(10 \mathrm{mmol})$; phenol $(10 \mathrm{mmol})$; water $(10 \mathrm{mmol})$; hydroxyacetone $(1.4 \mathrm{mmol})$ or 2-hydroxymethylfuran $(1.0 \mathrm{mmol})$ or D-glucose $(0.6 \mathrm{mmol}))$; ${ }^{\mathrm{b}}$ Unkown compound; ${ }^{\mathrm{c}}$ Anhydrosugar: 1,6-Anhydro-3,4-dideoxy- $\beta$-D-manno-hexapyranose; ${ }^{\mathrm{d}} \mathrm{GC}$ area\% of involved compounds versus the sum of the GC area\% of all products remained after the reaction.

Table 9. Products formed from hydroxyacetone or 2-hydroxymethylfuran on heating at $100{ }^{\circ} \mathrm{C}$ over $30 \% \mathrm{Cs}_{2.5} / \mathrm{K} 10$ for $1 \mathrm{~h}^{\mathrm{a}}$.

\begin{tabular}{cc|cc}
\hline \multicolumn{2}{c|}{ 2-Hydroxymethylfuran } & \multicolumn{2}{c}{ Hydroxyacetone } \\
\hline Compounds & Peak area (\%) & Compounds & Peak area (\%) \\
\hline 2-hydroxymethylfuran & 78.3 & Propionic acid & 63.4 \\
Difurfuryl ether & 9.4 & Hydroxyacetone dimers & 24.8 \\
5-Furfuryl-furfuryl alcohol & 4.9 & Methyl cyclopentenolone & 9.7 \\
Difuran-2-ylmethane & 4.8 & Unkown species & 1.8 \\
Others & 2.6 & & \\
\hline
\end{tabular}

a Products were analyzed by GC/MS. Each product was identified by excellent matches of their MS fragmentation patterns.

A large number of compounds with hydroxyl groups, particularly, anhydro monosaccharides such as levoglucosan, were derived from pyrolysis of cellulose and hemicellulose components of the pine wood feed during bio-oil production [5]. Anhydro monosaccharides readily hydrate back to monosaccharides when heated with acid and water. Therefore, the effects of D-glucose addition on 1-octene reactions with phenol/water over $\mathrm{Cs}_{2.5} / \mathrm{K} 10$, DX2, A15 and SSA catalysts were studied at $120{ }^{\circ} \mathrm{C}$ for $3 \mathrm{~h}$ (Table 8). SSA gives a higher activity than DX2, A15 and $\mathrm{Cs}_{2.5} / \mathrm{K} 10$. Trace amounts 
of octyl formates were formed over A15 and DX2 by esterification of formic acid by octanols. The formic acid was generated by the known acid-catalyzed conversions pathways of D-glucose (Scheme 7) [2,27]. 5-Hydroxymethylfurfural (HMF) was formed by D-glucose dehydration. Then, subsequent HMF hydration to its hemiacetal occurred in acidic media, followed by rehydration, ring-opening, loss of both water and formic acid to form levulinic acid. Also, small amounts of 1,6-anhydro-3,4-dideoxy- $\beta$-D-mannohexapyranose, generated by dehydration of D-glucose, were detected over SSA and $\mathrm{Cs}_{2.5} / \mathrm{K} 10$.

Scheme 5. Acid-catalyzed reactions of hydroxyacetone.

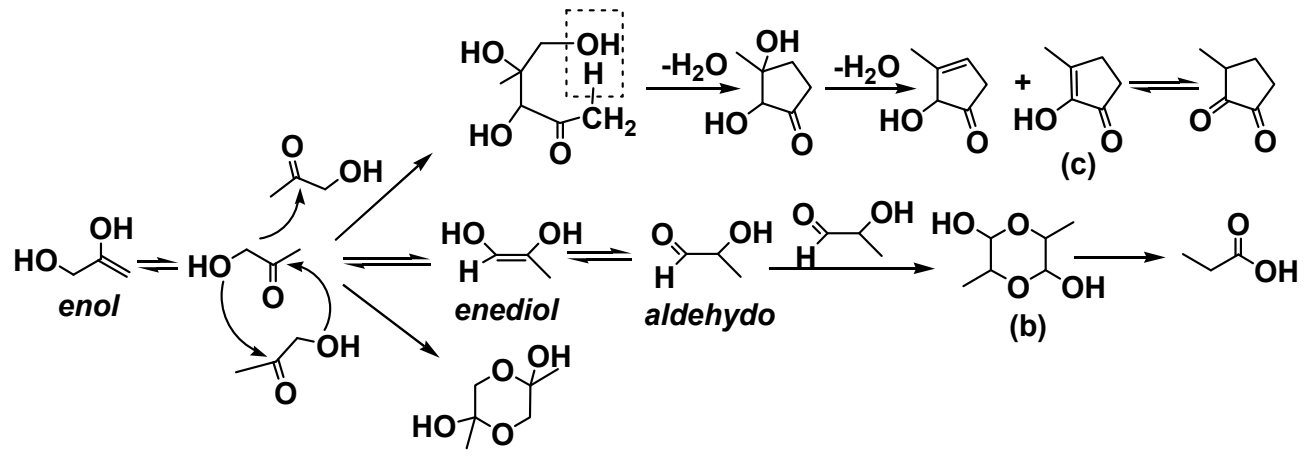

(a)

Scheme 6. Acid-catalyzed reactions of 2-hydroxymethylfuran.

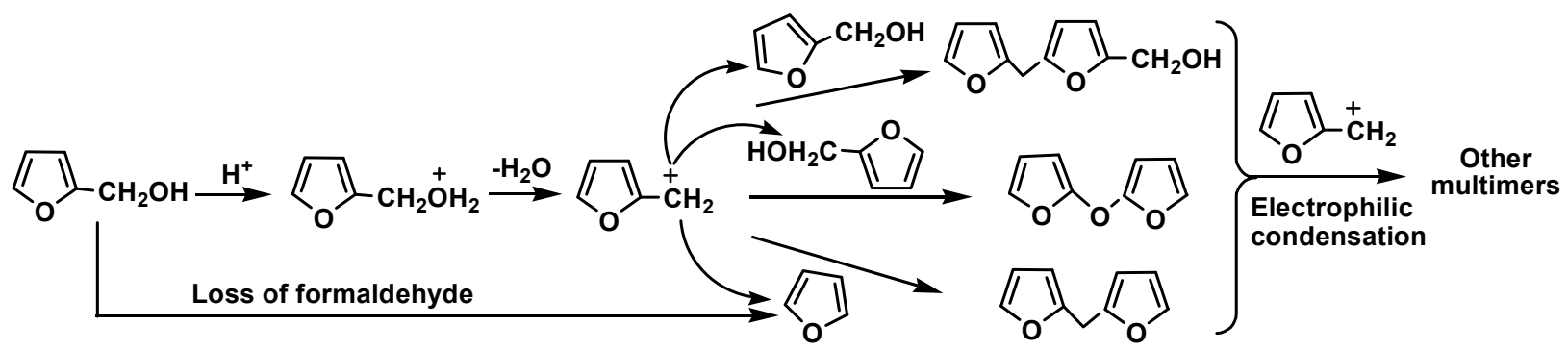

Scheme 7. Acid-catalyzed reactions of D-glucose as model monosaccharide [27].

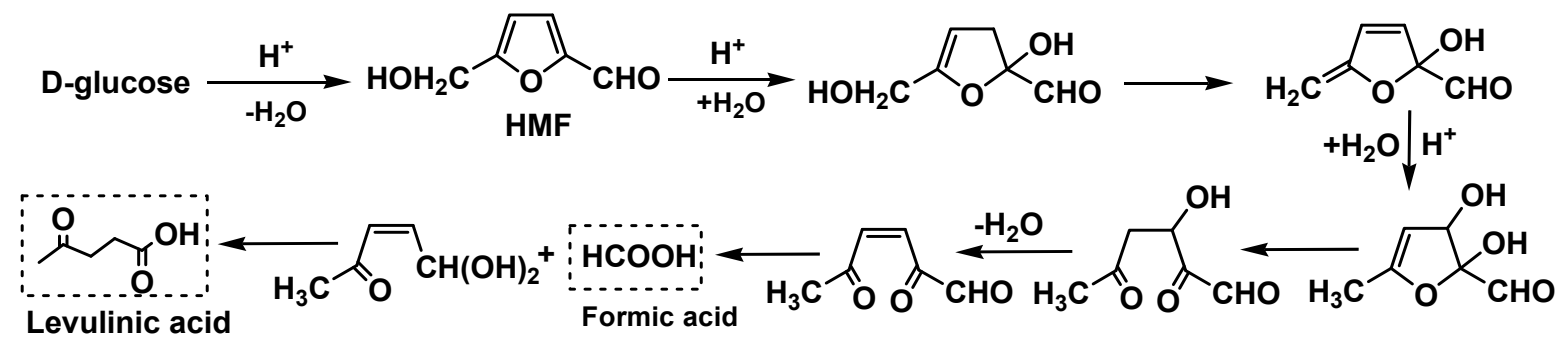

In addition to the reactions discussed above occurring between 1-octene with model bio-oil components, some additional olefin reactions took place. Table 10 shows the product distributions of individual olefin reactions conducted using equimolar amounts of olefin (1,7-octadiene, cyclohexene, 1-octene, or 2,4,4-trimethylpentene)/phenol/water over SSA at $120{ }^{\circ} \mathrm{C}$ for $3 \mathrm{~h}$. Skeletal isomerization reactions of all olefins occurred except with cyclohexene. Intramolecular diene cyclizations occurred for 1,7-octadiene, individually. 
No oligomerization or cracking of either 1-octene or 1,7-octadiene occurred. However, 1-octene isomers were detected in the reactions where neat phenol and 1 -octene operated at $100{ }^{\circ} \mathrm{C}$ over $\mathrm{Cs}_{2.5} / \mathrm{K} 10$ or A15 catalysts. 2,4,4-Trimethylpentene oligomerized to C16 olefins and cracked into C4 olefins readily at these conditions. Cracking of 2,4,4-trimethylpentene mainly produced isobutene. Cyclohexene's dimer 1-cyclohexyl-1-cyclohexene was found. Reoligomerization of isobutene gave C8, C12, and C16 olefins. Hydration reactions to form alcohols occurred for all olefins, followed by etherification of these resulting alcohols generating ethers and water (Scheme 8). Thus, the choice of olefin structure will play a role in the product distribution observed, but all the olefins help drive the upgrading process to remove water and promote esterification, acetal formation, generate ethers and both $O$ - and $C$-alkylate phenols.

Table 10. Product distributions and phenol conversions in addition reactions by different olefins in phenol/water at $120^{\circ} \mathrm{C}$ in 3 h over the SSA catalyst ${ }^{\mathrm{a}}$.

\begin{tabular}{|c|c|c|}
\hline Olefins & $\mathrm{PC}(\%)^{\mathrm{b}}$ & Product distributions (GC area \%) ${ }^{c}$ \\
\hline 1,7-Octadiene & 52.4 & $\begin{array}{l}\text { Skeletal isomers (4.5\%): 1,6-octadiene, 3,5-octadiene, 2-methyl-1,5-heptadiene, } \\
\text { 2,4-dimethyl-1,5-hexadiene, 3-methyl-1,5-heptadiene, etc. } \\
\text { Cycloolefins (14.2\%): bicyclo[4.1.0]heptane, 2-methylbicyclo[2.2.1]heptane, } \\
\text { 4-ethyl-1-cyclohexene,cyclooctene,1-ethyl-2-methylcyclopen-tene, } \\
\text { 1,6-dimethyl-cyclohexene,ethylidenecyclohexane, 1,2-dimethyl-1-cyclohexene, etc. } \\
\text { Alcohols and ethers (8.8\%): 1,7-octanediol, 4-ethylcyclohexanol, 1-ethylcyclohexanol, } \\
\text { 2-propyl-tetrahydropyran, 2,5-diethyltetrahydrofur-an, 2-propyltetrahydropyran, } \\
\text { 2-butyl-3-ethyloxirane, etc. } \\
\text { O-Alkylates (33.4\%); Mono-C-alkylates } \mathbf{( 4 . 1 \% ) ; ~ D i - C - a l k y l a t e s ~} \mathbf{( 1 0 . 1 \% )}\end{array}$ \\
\hline Cyclohexene & 62.0 & 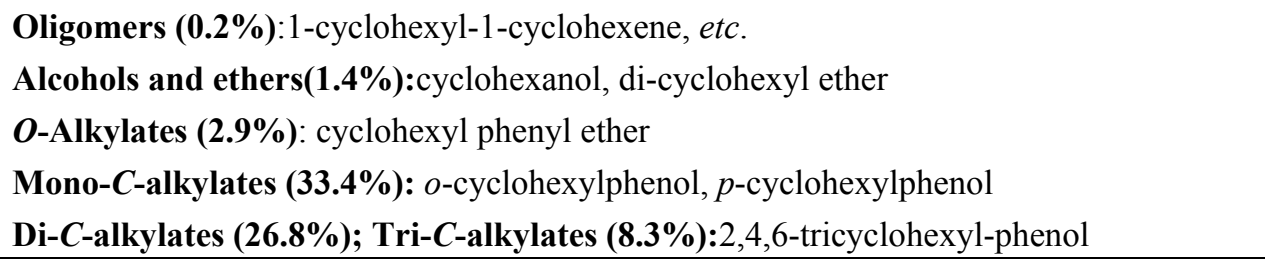 \\
\hline 1-Octene & 74.5 & $\begin{array}{l}\text { Skeletal isomers (12.1\%):2-octene, 3-octene, 4-ocene, 1-octene. } \\
\text { Alcohols and ethers (5.1\%):2-octanol, 3-octanol dioctyl ethers, etc. } \\
\text { O-Alkylates (48.6\%):2-Octyl phenyl ether, 3-Octyl phenyl ether, etc. } \\
\text { Mono-C-alkylates (14.5\%): } o \text {-octylphenol, } p \text {-octylphenols, etc. } \\
\text { Di- } \boldsymbol{C} \text {-alkylates (11.5\%): } 2,4 \text {-di-octylphenols, } 2,6 \text {-dioctylphenols, }\end{array}$ \\
\hline $\begin{array}{l}\text { 2,4,4-Trimethyl } \\
\text {-pentene }\end{array}$ & 89.9 & 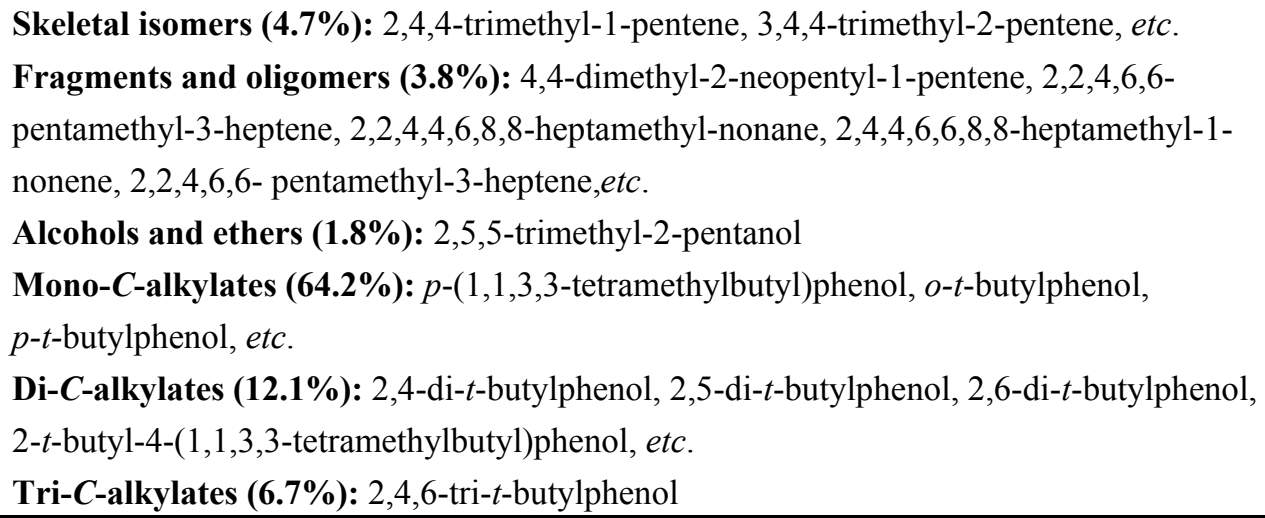 \\
\hline
\end{tabular}

${ }^{\mathrm{a}}$ Reaction conditions: (SSA, 0.15 g; olefin: phenol: water $(\mathrm{mmol})=10: 10: 10 ;{ }^{\mathrm{b}}$ Phenol conversions; ${ }^{\mathrm{c}} \mathrm{GC}$ area $\%$ of involved compounds versus the sum of the GC area $\%$ of all products remained after the reaction. 
Scheme 8. Acid-catalyzed reactions of olefin reagents.

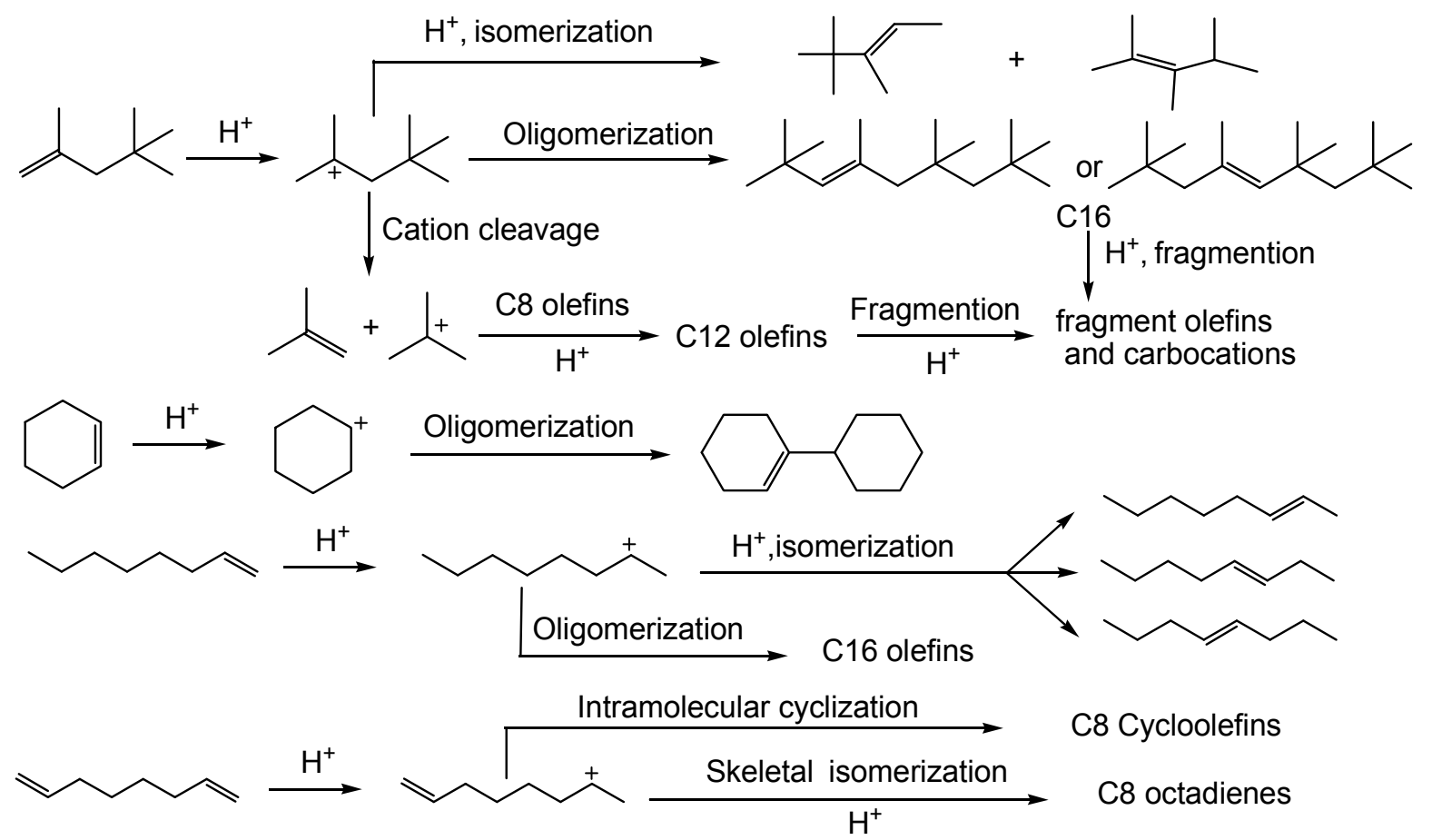

In addition, intermolecular dehydration of 1-butanol occurred producing dibutyl ether with both Dowex50WX2 and SSA (Table 11). Also, traces of butyl phenyl ether were formed. Small amounts of $t$-butyl phenols $(0.9 \%)$ were detected when 2-butanol was used as replacement of 1-butanol over SSA. Under acid catalyzed conditions, 2-butanol was protonated, and then dehydrated generating secondary carbocations. Some isomerization to tertiary carbocations must then occur. Phenol added to these $\mathrm{C} 4$ cations generating $O$-t-butylated phenol, followed by isomerization of the $t$-butyl phenyl ether to the thermodynamic $C$-t-butylated phenol products along with some bis-alkylated phenols formation (Scheme 9). Also, both acetic acid esterification and acetaldehyde acetalation reactions with 1-butanol occurred, generating butyl acetate and 1,1-dibutoxyethane (acetal), respectively, when acetic acid and acetaldehyde were present.

Table 11. Product distributions and 1-butanol conversions in acid-catalyzed 1-octene/ 1-butanol reactions with phenol/water at $120^{\circ} \mathrm{C}^{\mathrm{a}}$.

\begin{tabular}{ccccc|cccc}
\hline & & \multicolumn{3}{c|}{ Selectivity (\%) } & \multicolumn{4}{c}{ Yield (\%) } \\
Catalyst & $\begin{array}{c}\text { 1-Butanol } \\
\text { Conv. (\%) }\end{array}$ & $\begin{array}{c}\text { Mono- } \boldsymbol{O} \text { - } \\
\text { octylates }\end{array}$ & $\begin{array}{c}\text { Mono- } \boldsymbol{C} \text { - } \\
\text { octylates }\end{array}$ & Di-octylates & Octanols & $\begin{array}{c}\text { Dioctyl } \\
\text { ethers }\end{array}$ & $\begin{array}{c}\text { Dibutyl } \\
\text { ether }\end{array}$ & O-Butylate \\
\hline A15 & 60.9 & 84.2 & 14.5 & 1.2 & 6.3 & 2.0 & 11.9 & 0.14 \\
DX2 & 58.7 & 84.8 & 14.1 & 1.0 & 6.9 & 2.1 & 11.9 & 0.61 \\
SSA & 74.8 & 82.3 & 13.8 & 3.9 & 4.8 & 1.9 & 12.4 & 0.1 \\
$\mathrm{Cs}_{2.5} / \mathrm{K} 10$ & 8.2 & 53.4 & 46.6 & 0 & 0.1 & $\mathrm{Nd}$ & 0.1 & $\mathrm{Nd}$ \\
\hline
\end{tabular}

${ }^{\mathrm{a}}$ Reaction conditions: (solid catalyst, $0.15 \mathrm{~g}$; time: $3 \mathrm{~h}$; 1-octene: phenol: water: 1-butanol $(\mathrm{mmol})=$ 10:10:11.6:3.4; ${ }^{\mathrm{b}} \mathrm{GC}$ area\% of involved compounds versus the sum of the GC area\% of all products remained after the reaction. 
Scheme 9. Acid-catalyzed reactions of model bio-oil components with alcohol.

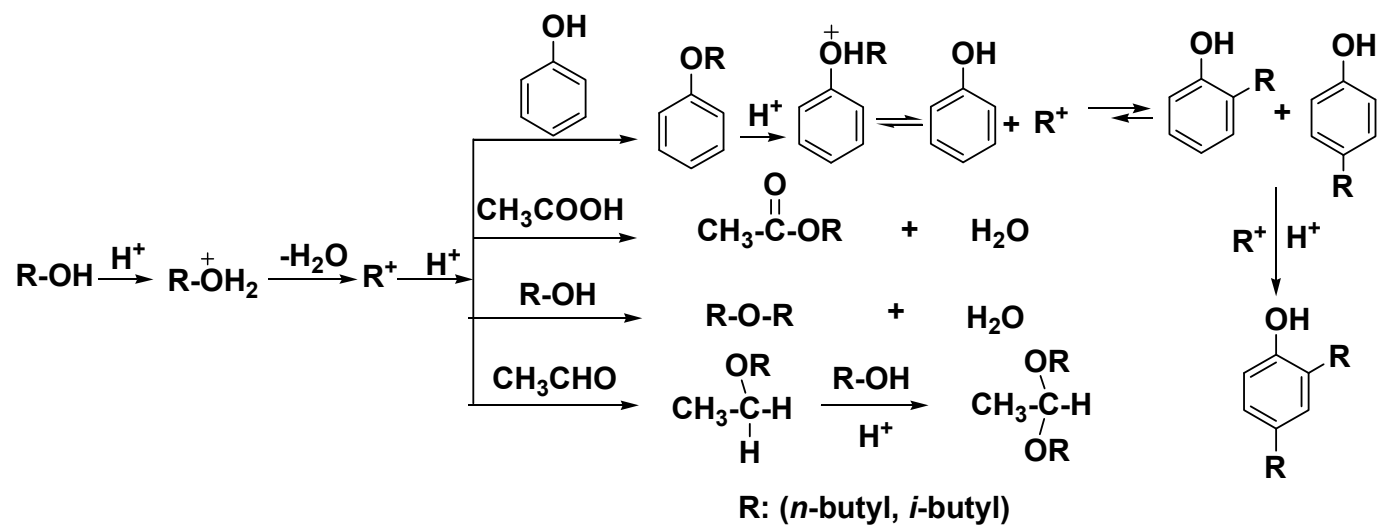

Table 12 summarizes the product compositions of the model bio-oil (phenol/water/acetic acid/acetaldehyde/hydroxyacetone/D-glucose/2-hydroxymethylfuran mixtures) reactions with 1-octene/1-butanol over all five acid catalysts at $120{ }^{\circ} \mathrm{C}$ for $3 \mathrm{~h} \mathrm{[22].}$

Table 12. Product compositions of model bio-oil reactions with 1-octene/1-butanol over $\mathrm{Cs}_{2.5} / \mathrm{K} 10, \mathrm{~A} 15, \mathrm{~A} 36, \mathrm{DX} 2$ and SSA catalysts at $120^{\circ} \mathrm{C}$ in $3 \mathrm{~h}^{\mathrm{a}}$.

\begin{tabular}{llllll}
\hline \multirow{2}{*}{ Products } & \multicolumn{5}{c}{ Peak area (\%) } \\
\cline { 2 - 6 } Unreacted & $\mathbf{C s}_{2.5} / \mathbf{K 1 0}$ & $\mathbf{A 3 6}$ & $\mathbf{A 1 5}$ & $\mathbf{D X 2}$ & SSA \\
1-octene & 48.4 & 54.1 & 26.4 & 20.3 & 4.0 \\
1-butanol & 1.0 & 0.2 & 0.1 & 0.3 & 0.2 \\
phenol & 40.4 & 21.9 & 15.7 & 15.3 & 9.6 \\
1-Dodecane (Internal standard) & 1.4 & 1.4 & 1.5 & 1.8 & 3.0 \\
\hline In common & & & & & \\
1-Octene isomers & 1.0 & 8.5 & 31.1 & 25.3 & 28.9 \\
Phenol octylates & 0.8 & 2.9 & 12.4 & 18.8 & 35.3 \\
Octanols & 0.1 & 2.3 & 2.6 & 3.8 & 1.5 \\
Dioctyl ethers & 0.1 & $\mathrm{Nd}$ & 0.1 & 0.3 & 1.3 \\
b 1-Octene oligmers and their hydrates & 3.8 & 4.2 & 4.7 & 5.0 & 6.1 \\
Octyl acetates & 0.8 & 0.9 & 1.6 & 6.7 & 4.8 \\
1,1-Dibutoxyethane & 0.3 & 0.1 & 0.1 & 0.1 & 0.1 \\
Dibutyl ether & 1.4 & 0.1 & 0.3 & 0.4 & 2.7 \\
Butyl acetate & 0.3 & 2.9 & 3.0 & 1.7 & 2.3 \\
Butyl levulinate & 0.1 & 0.6 & 0.3 & 0.2 & 0.4 \\
\hline Independent & & & & & \\
2-Hydroxy-3-methylcyclopent-2-enone & 0.1 & $\mathrm{Nd}$ & 0.1 & 0.1 & $\mathrm{Nd}$ \\
2-(2-Furylmethyl)furan & 0.1 & $\mathrm{Nd}$ & $\mathrm{Nd}$ & $\mathrm{Nd}$ & $\mathrm{Nd}$ \\
\hline
\end{tabular}

${ }^{a}$ Reaction conditions: (catalyst, 0.15 g; 1-octene: 1-butanol: phenol: water: acetic acid: acetaldehyde: hydroxyacetone: D-glucose: 2-hydroxymethylfuran $(\mathrm{g})=1.35: 0.15: 0.94: 0.15: 0.15: 0.12: 0.12: 0.15: 0.15$; time: $3 \mathrm{~h}$; nd: not detected); these results were first noted in the preliminary communication of this work found in reference $23 ;{ }^{b} \mathrm{C} 8, \mathrm{C} 16$ and $\mathrm{C} 24$ olefins and their hydrates.

In addition to alkylated phenols (both $O$-octylated and $C$-octylated), octanols, dibutyl ether and dioctyl ether, butyl acetate and various octyl acetates, 1-octene oligomers and isomers mentioned 
above, 1,1-dibutoxyethane and butyl levulinate were formed over all the catalysts. 1,1-Dibutoxyethane was formed by acetal formation between acetaldehyde and 1-butanol (Scheme 9). Levulinic acid reacted with 1-butanol forming butyl levulinate. Levulinic acid was derived from the acid-catalyzed conversions of both D-glucose (Scheme 7) and 2-hydroxymethylfuran (Scheme 10), which are both known pathways. Levulinic acid has been obtained by dehydration of hexoses to 5-hydroxymethylfurfural (HMF) and its subsequent hydration in acidic media [2,28]. Acid-catalyzed conversion of 2-hydroxymethylfuran to levulinic acid in aqueous solutions also has been recently reported [29].

Scheme 10. Acid-catalyzed conversion of 2-hydroxymethylfuran to levulinic acid in aqueous solution [29].

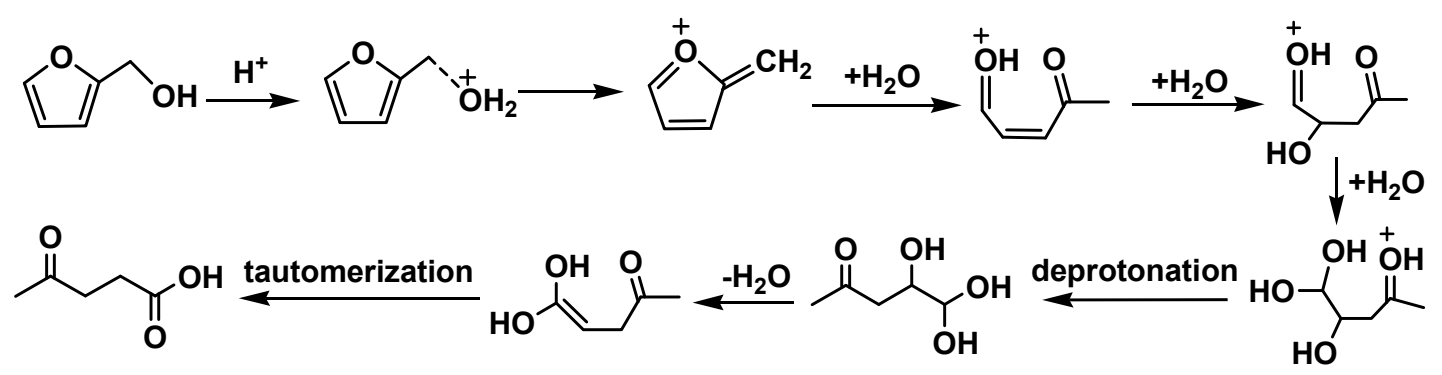

Butyl levulinate shows the extent of levulinic acid formation. Table 13 demonstrates that it originates from both D-glucose and 2-hydroxymethylfuran. Increasing butyl levulinate formation was observed when the amount of 2-hydroxymethylfuran and D-glucose were increased in the model bio-oil [22]. Trace amounts of 3-methyl-2-hydroxycyclopent-2-enone were generated from hydroxyacetone over $\mathrm{Cs}_{2.5} / \mathrm{K} 10$, A15 and DX2 catalysts. Among the new products formed, 1-octene oligomers were the most abundant components over $\mathrm{Cs}_{2.5} / \mathrm{K} 10$ or A36. However, phenol alkylates became the most abundant products for the other three catalysts. Trace amount of 2-(2-furylmethyl) furan, formed by furfuryl alcohol polymerization, was detected over the $\mathrm{Cs}_{2.5} / \mathrm{K} 10$ catalyst. No 2-(2-furylmethyl) furan was detected over other catalysts, because all the reactive furan products were consumed by these more acidic catalysts.

Table 13. Butyl levulinate yields obtained from reactions of 1-octene/1-butanol with model bio-oils containing different amounts of D-glucose, 2-hydroxymethylfuran and 1-butanol at $120^{\circ} \mathrm{C}$ in $3 \mathrm{~h}$ over Dowex $50 \mathrm{WX} 2{ }^{\mathrm{a}}$.

\begin{tabular}{cccc}
\hline \multicolumn{2}{c}{ Addition amounts (g) } & $\begin{array}{c}\text { Butyl levulinate yields } \\
\text { (Area \%) }\end{array}$ \\
\hline 2-Hydroxymethylfuran & D-glucose & 1-Butanol & 0.22 \\
0.15 & 0.15 & 0.15 & 0.34 \\
0.15 & 0.30 & 0.30 & 0.98 \\
0.15 & 0.30 & 0.30 & 1.39 \\
0.30 & 0.15 & 0.30 & 2.45 \\
0.30 & 0.30 & 0.60 & \\
\hline
\end{tabular}

a Reaction conditions: (catalyst, $0.15 \mathrm{~g}$; 1-octene: 1-butanol: phenol: water: acetic acid: acetaldehyde: hydroxyacetone: D-glucose: 2-hydroxymethylfuran $(\mathrm{g})=1.35:(0.15 \sim 0.6): 0.94: 0.15: 0.15: 0.12: 0.12$ : $(0.15 \sim 0.3)$ : $(0.15 \sim 0.3)$; these results were first noted in the preliminary communication of this work found in Reference [22]. 


\subsection{Proposed Reaction Pathways for Model Bio-Oil Components}

A complicated but clear reaction pathway is postulated and shown in Figure 2 based on the detailed product analyses and discussions mentioned above. Under acid-catalyzed conditions, olefin protonation and subsequent proton loss and reprotonation steps generated the isomerized olefins and their cation intermediates. Simultaneously, a series of competing reactions occur, where bio-oil's components (water, carboxylic acids, phenols and alcohols) and the added olefins add to these cations. This leads to hydration, esterification, $O$-alkylation, etherification and oligomerization which forms alcohols, esters, phenol $O$-alkylates, ethers and olefin oligomers, respectively. Moreover, diene intermolecular cyclizations and branched olefin cracking into small fragments as well as reoligomerization of these small fragments occurred. Similarly, under acid catalyzed conditions, protonation of alcohols and subsequent dehydration of these protonated products occurred generating carbocations. Meanwhile, additional competing reactions among carboxylic acids, aldehydes, alcohols, phenols and levulinic acid with these carbocations occurred, generating esters, acetals, ethers, phenol O-alkylates and alkyl levulinates, respectively. $O$-Alkylated phenols isomerized to the thermodynamic $C$-alkylated phenol via a Friedel Crafts mechanism. Further addition of carbocations to mono-alkylated phenols generated bis-alkylated phenols.

In addition to reactions between bio-oil components and olefin/alcohol reagents, the added alcohol adds across olefins to give intermolecular etherification. Self-etherification of the added alcohol reagent also occurs. These reactions occur simultaneously, generating corresponding ethers. Acid-catalyzed dehydration of D-glucose to levulinic acid [28] occurred. First, dehydration of D-glucose gives 5-hydroxymethylfurfural (HMF). Then, HMF hydration to its hemiacetal occurred followed by sequential rehydration, ring-opening, loss of both water and formic acid generating levulinic acid. Also, acid-catalyzed 2-hydroxymethylfuran rehydration and subsequent ring opening, dehydration and tautomerization formed levulinic acid [29]. Levulinic acid, in turn, is converted to alkyl levulinates by alcohols. Independently, polymerization of 2-hydroxymethylfuran via electrophilic aromatic substitution proceeded jointly with loss of formaldehyde to form oligomeric products. Simultaneous dimerization and isomerization of hydroxyacetone occurred, forming cyclic hydroxyacetone dimers and propionic acid along with some 2-hydroxy-3-methylcyclopent-2-enone. This latter product was likely formed by aldol condensation of hydroxyacetone to an open hydroxyacetone dimer and its subsequent dehydration and cyclodehydration reactions.

Clearly, bio-oil upgrading by simultaneous reactions with olefin/alcohol over solid acids is complex, involving many simultaneous equilibria and competing reactions. However, the key reason for the success of this upgrading process is the role of acid-catalyzed olefin hydration. Olefin hydration removes water. As water concentration drops, esterification and acetal formation equilibria shift toward ester and acetal products. 
Figure 2. Reaction pathways of the model bio-oil components during upgrading with olefin/alcohol over solid acid catalysts.

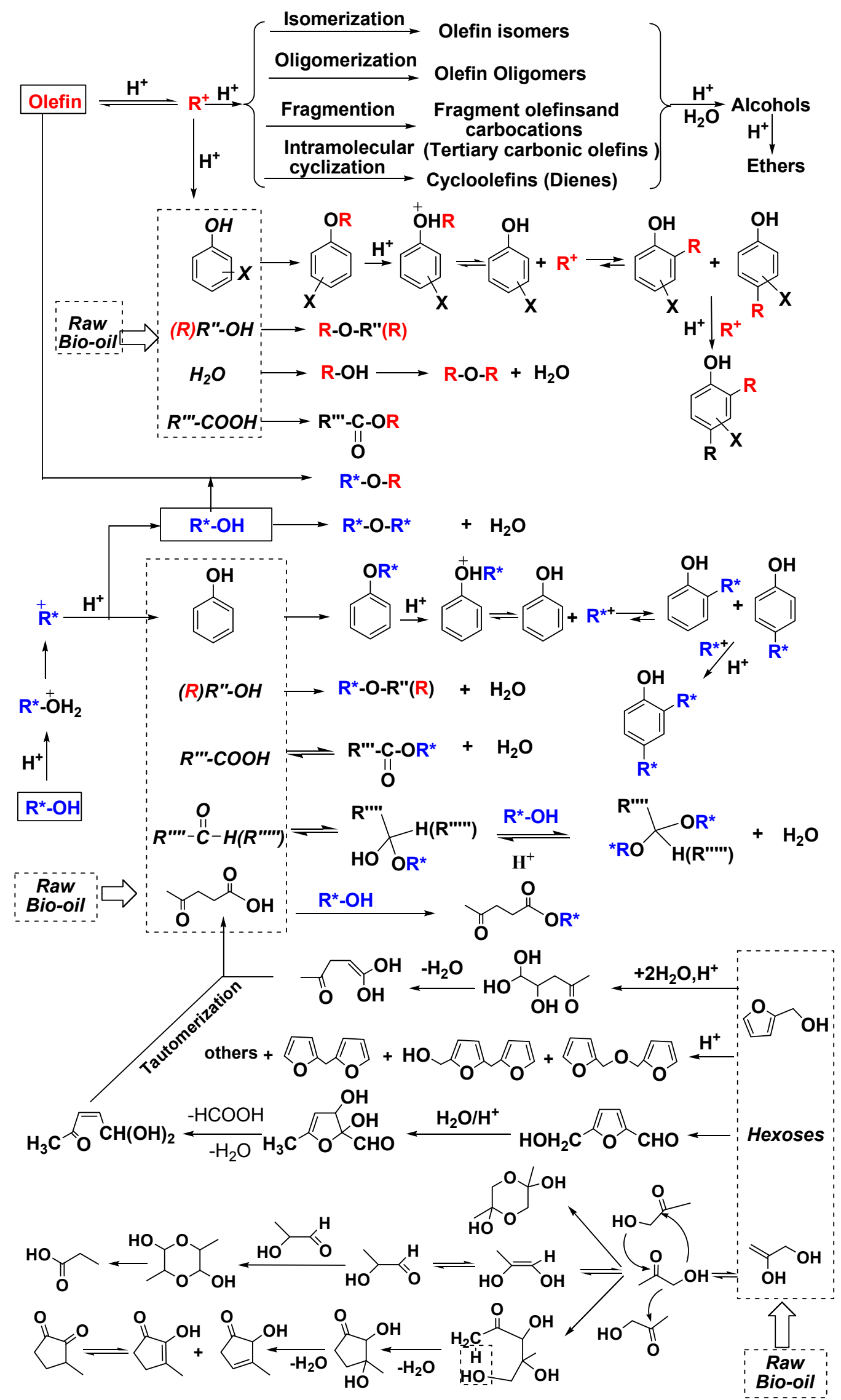




\section{Experimental Section}

All chemicals were purchased from Sigma Aldrich (St. Louis, MO, USA), and used without further purification unless otherwise noted.

\subsection{Catalyst Preparation}

The silica gel, Kieselgel 40 (4 nm mean pore diameter, $\left.590 \mathrm{~m}^{2} \cdot \mathrm{g}^{-1}\right)$, was dried at $120{ }^{\circ} \mathrm{C}$ for $3 \mathrm{~h}$ in air prior to its use. The following SSA catalyst was prepared by a well-developed procedure [23,30]. A $250 \mathrm{~mL}$ suction flask, equipped with a constant pressure dropping funnel containing $5.83 \mathrm{~g}$ chlorosulfonic acid and a gas inlet tube for releasing $\mathrm{HCl}$ gas, was charged with $10.0 \mathrm{~g}$ Kieselgel 40 silica gel and $50 \mathrm{~mL} \mathrm{CH}_{2} \mathrm{Cl}_{2}$. Chlorosulfonic acid was added dropwise over $30 \mathrm{~min}$ while stirring at room temperature. $\mathrm{HCl}$ gas was immediately evolved and absorbed into water. The mixture was then stirred for another $30 \mathrm{~min}$. Next, $\mathrm{CH}_{2} \mathrm{Cl}_{2}$ was removed by rotary evaporation $\left(50{ }^{\circ} \mathrm{C}, 20 \mathrm{~min}\right)$. A white solid (SSA, yield, 98\%) was obtained and stored in a desiccator until use. K10 clay supported $\mathrm{Cs}_{2.5} \mathrm{H}_{0.5} \mathrm{PW}_{12} \mathrm{O}_{40}$ catalyst (hereafter designated $\mathrm{Cs}_{2.5} / \mathrm{K} 10$ ) was prepared by a well-developed route [31]. Typical Fourier Transform Infrared (FTIR) spectra of these two catalysts were recorded on a Thermo Scientific Nicolet 6700 spectrophotometer. Surface area, total pore volume and pore diameter of the catalysts were determined by $\mathrm{N}_{2}$ adsorption at $77 \mathrm{~K}$ using a Quantachrome Nova 2000 instrument after evacuating at $393 \mathrm{~K}$ for $3 \mathrm{~h}$ under nitrogen atmospheric. The total amount of acidity $\left(\mathrm{H}^{+}\right)$was measured by titration of catalyst samples in water with standardized sodium hydroxide (0.495 M).

\subsection{Catalytic Reactions}

All reactions were carried out in glass pressure reaction vessels equipped with a magnetic stirrer. The temperature, controlled using an external oil bath, was raised to the desired value $\left(100{ }^{\circ} \mathrm{C}\right.$ or $\left.120^{\circ} \mathrm{C}\right)$ and held for the desired time $(1 \mathrm{~h}$ or $3 \mathrm{~h})$ with vigorous stirring. In a typical reaction, SSA $(0.15 \mathrm{~g})$, 1-octene (1.35 g), 1-butanol (0.15 g), phenol (0.94 g), water $(0.15 \mathrm{~g})$, acetic acid ( $0.15 \mathrm{~g})$, acetaldehyde $(0.12 \mathrm{~g})$, hydroxyacetone $(0.12 \mathrm{~g})$, D-glucose $(0.15 \mathrm{~g}), 2$-hydroxymethylfuran $(0.15 \mathrm{~g})$ and the internal standard (99.9\% 1-dodecane, $0.02 \mathrm{~g}$ ) were charged in that order. Catalysts studied included SSA, $\mathrm{Cs}_{2.5} / \mathrm{K} 10, \mathrm{~A} 15$, A36 and DX2. After reaction (typically, $3 \mathrm{~h}$ ), all products were diluted in methanol and identified by analysis on a Shimadzu QP2010S gas chromatograph equipped with a mass selective detector (GC-MS) using helium as the carrier gas. A SHRXI-5MS $(30 \mathrm{~m} \times 0.25 \mathrm{~mm}$ I.D. $\times 0.25 \mu \mathrm{m}$ film) capillary column was used with a 50:1 split ratio and a solvent cut time of 3 min. The temperature program, started at $30{ }^{\circ} \mathrm{C}(5 \mathrm{~min})$, was ramped from 30 to $300{ }^{\circ} \mathrm{C}$ at $10{ }^{\circ} \mathrm{C} / \mathrm{min}$ and held at $300{ }^{\circ} \mathrm{C}$ for $8 \mathrm{~min}$. An auto-sampler and the same analysis method were used for all product analyses. MS identification of the products was based on molecular mass, fragmentation patterns and by matching the spectra with a digital compound library. The percent phenol conversion to other products in the upgrading reactions was determined by the change in peak area versus that of the 1-dodecane internal standard. 


\section{Conclusions}

Liquid phase supported acid-catalyzed olefin/alcohol reactions with model bio-oils indicate that silica sulfuric acid is an improved catalyst with greater hydrothermal stability and catalytic activity over $\mathrm{Cs}_{2.5} / \mathrm{K} 10$ and other resin sulfonic acids. Development and demonstration of this improved catalyst meets one goal of this study. $\mathrm{Cs}_{2.5} / \mathrm{K} 10$ lost most of its catalytic activity, poisoned by the coke formation from hydroxyacetone, 2-hydroxymethylfuran and D-glucose. Decomposition of resin-bound sulfonic acids occurred.

The use of different olefins and alcohols leads to different product selectivities. This study has demonstrated many of the competing reaction pathways which occur in bio-oil upgrading by acid-catalyzed alcohol/olefin treatment in much greater detail than all previous work, thereby accomplishing a second major goal of this work. Upgrading bio-oil via simultaneous reactions with olefin/alcohol under acid-catalyzed conditions was complex, involving many simultaneous equilibria and competing reactions. These reactions mainly include phenol alkylation, olefin hydration, esterification, etherification, acetal formation, olefin isomerization and oligomerization, cracking and reoligomerization of tertiary cation centers from protonated olefins and their fragments, hydroxyacetone dimerization (including cyclization) and intermolecular aldol condensation. Also, levulinic acid formation both from sequential dehydration, ring contractions, hydrations and ring opening of monosaccharides, and from sequential rehydration, ring opening, dehydration and tautomerization of 2-hydroxymethylfuran occurred. Synergistic interactions among reactants and products were determined.

Water removal by acid-catalyzed olefin hydration is the key reason for the success of this upgrading process. As water concentration drops, esterification and acetal formation equilibria shift toward ester and acetal products. In turn, the formed esters and acetals as well as the added alcohol help reduce the phase separation present between hydrophilic bio-oil and hydrophobic olefin. All of this occurs while maintaining all the caloric value of both the raw bio-oil and the alcohol and olefin reagents. This work also provides further insight into the complexity of this bio-oil upgrading approach.

\section{Acknowledgments}

This material is based upon work performed through MOE Key Laboratory of Bio-based Material Science and Technology at the Northeast Forestry University, China and Department of Chemistry at Mississippi State University. This work was supported by the National Key Technologies R\&D Program of China under the Project Number 2012BAD32B04.

\section{References}

1. Ragauskas, A.J.; Williams, C.K.; Davison, B.H.; Britovsek, G.; Cairney, J.; Eckert, C.A.; Frederick, W.J., Jr.; Hallett, J.P.; Leak, D.J.; Liotta, C.L.; et al. The path forward for biofuels and biomaterials. Science 2006, 311, 484-489.

2. Huber, G.W.; Iborra, S.; Corma, A. Synthesis of transportation fuels from biomass: Chemistry, catalysts, and engineering. Chem. Rev. 2006, 106, 4044-4098. 
3. Amidon, T.E.; Wood, C.D.; Shupe, A.M.; Wang, Y.; Graves, M.; Liu, S.J. Biorefinery: Conversion of woody biomass to chemicals, energy and materials. J. Biobased Mater. Bioenergy 2008, 2, 100-120.

4. Butt, D. Thermochemical Processing of Agroforestry Biomass for Furans, Phenols, Cellulose and Essential Oils; Final Report for RIRDC Project PN99.2006; RIRDC Publication (No.06/121): Melbourne, Australia, 2006.

5. Mohan, D.; Pittman, C.U., Jr.; Steele, P.H. Pyrolysis of wood/biomass for bio-oil: A critical review. Energy Fuels 2006, 20, 848-889.

6. Czernik, S.; Bridgwater, A.V. Overview of applications of biomass fast pyrolysis oil. Energy Fuels 2004, 18, 590-598.

7. Diebold, J.P. A review of the chemical and physical mechanisms of the storage stability of fast pyrolysis bio-oils. In Fast Pyrolysis of Biomass: A Handbook; CPL Scientific Publishing: Newbury, UK, 2002; Volume 2, pp. 243-292.

8. Elliot, D.C.; Hart, T.R.; Neuenschwander, G.G.; Rotness, L.J.; Zacher, A.H. Catalytic hydroprocessing of biomass fast pyrolysis bio-oil to produce hydrocarbon products. Environ. Progr. Sustain. Energy 2009, 28, 441-449.

9. Ben, H.; Mu, W.; Deng, Y.; Ragauskas, A.J. Production of renewable gasoline from aqueous phase hydrogenation of lignin pyrolysis oil. Fuel 2013, 103, 1148-1153.

10. Venderbosch, R.H.; Prins, W. Fast pyrolysis technology development. Biofuels Bioprod. Biorefin. 2010, 4, 178-208.

11. Mortensen, P.M.; Grunwaldt, J.D.; Jensen, P.A.; Knudsen, K.G.; Jensen, A.D. A review of catalytic upgrading of bio-oil to engine fuels. Appl. Catal. A 2011, 407, 1-19.

12. Bulushev, D.A.; Ross, J.R.H. Catalysis for conversion of biomass to fuels via pyrolysis and gasification: A review. Catal. Today 2011, 171, 1-13.

13. Bridgwater, A.V. Review of fast pyrolysis of biomass and product upgrading. Biomass Bioenergy 2012, 38, 68-94.

14. Zhang, H.; Xiao, R.; Wang, D.; He, G.; Shao, S.; Zhang, J.; Zhong, Z. Biomass fast pyrolysis in a fluidized bed reactor under $\mathrm{N}_{2}, \mathrm{CO}_{2}, \mathrm{CO}$., $\mathrm{CH}_{4}$ and $\mathrm{H}_{2}$ atmospheres. Bioresour. Technol. 2011, $102,4258-4264$.

15. Zabeti, M.; Nguyen, T.S.; Lefferts, L.; Heeres, H.J.; Seshan, K. In situ catalytic pyrolysis of lignocellulose using alkali-modified amorphous silica alumina. Bioresour. Technol. 2012, 118, 374-381.

16. Wan, Y.Q.; Chen, P.; Zhang, B.; Yang, C.; Liu, Y.; Lin, X.; Ruan, R. Microwave-assisted pyrolysis of biomass: Catalysts to improve product selectivity. J. Anal. Appl. Pyrolysis 2009, 86, $161-167$.

17. Zhang, Z.J.; Wang, Q.W.; Yang, X.L.; Chatterjee, S.; Pittman, C.U., Jr. Sulfonic acid resin-catalyzed addition of phenols, carboxylic acids, and water to olefins: Model reactions for catalytic upgrading of bio-oil. Bioresour. Technol. 2010, 101, 3685-3695.

18. Yang, X.L.; Chatterjee, S.; Zhang, Z.J.; Zhu, X.F.; Pittman, C.U., Jr. Reactions of phenol, water, acetic acid, methanol, and 2-hydroxymethylfuran with olefins as models for bio-oil upgrading. Ind. Eng. Chem. Res. 2010, 49, 2003-2013. 
19. Zhang, Z.J.; Wang, Q.W.; Tripathi, P.; Pittman, C.U., Jr. Catalytic upgrading of bio-oil using 1-octene and 1-butanol over sulfonic acid resin catalysts. Green Chem. 2011, 13, 940-949.

20. Cheng, C.L.; Chien, L.J.; Lee, W.J.; Che, P.Y.; Chen, B.Y.; Chang, J.S. High yield bio-butanol production by solvent-producing bacterial microflora. Bioresour. Technol. 2012, 113, 58-64.

21. DuPont/BP. DuPont and BP Announce Partnership to Develop Advanced Biofuel; DuPont Press Release: Wilmington, NC, USA, 2006. Available online: http://multivu.prnewswire.com/mnr/ dupont/24656/ (accessed on 4 March 2013).

22. Zhang, Z.J.; Sui, S.J.; Tan, S.; Wang, Q.W.; Pittman, C.U., Jr. Catalytic conversion of bio-oil to oxygen-containing fuels by simultaneous reactions with 1-butanol and 1-octene over solid acids: Model compound studies and reaction pathways. Bioresour. Technol. 2012, 130, 789-792.

23. Minakata, S.; Komatsu, M. Organic reactions on silica in water. Chem. Rev. 2009, 109, 711-724.

24. Meng, F.B.; Zhang, B.Y.; Liu, L.M.; Zang, B.L. Liquid-crystalline elastomers produced by chemical crosslinking agents containing sulfonic acid groups. Polymer 2003, 44, 3935-3943.

25. Marcelo, E.; Domine, C.; Veen, V.; Schuurman, Y.; Mirodatos, C. Coprocessing of oxygenated biomass compounds and hydrocarbons for the production of sustainable fuel. ChemSusChem $\mathbf{2 0 0 8}$, 1, 179-181.

26. Corma, A.; Hube, G.W.; Sauvanaud, L.; O’Connor, P. Biomass to chemicals: Catalytic conversion of glycerol/water mixtures into acrolein, reaction network. J. Catal. 2008, 257, 163-171.

27. Kim, T.; Assary, R.S.; Marshall, C.L. Gosztola, D.J.; Curtiss, L.A.; Stair, P.C. Acid-catalyzed furfuryl alcohol polymerization: Characterizations of molecular structure and thermodynamic properties. ChemCatChem 2011, 3, 1451-1458.

28. Horvat, J.; Klaic, B.; Metelko, B.; Sunjic, V. Mechanism of levulinic acid formation. Tetrahedron. Lett. 1985, 26, 2111-2114.

29. González Maldonado, G.M.; Assary, R.S.; Dumesic, J.; Curtiss, L.A. Experimental and theoretical studies of the acid-catalyzed conversion of furfuryl alcohol to levulinic acid in aqueous solution. Energy Environ. Sci. 2012, 5, 6981-6989.

30. Shaabani, A.; Rahmati, A. Silica sulfuric acid as an efficient and recoverable catalyst for the synthesis of trisubstituted imidazoles. J. Mol. Catal. A 2006, 249, 246-248.

31. Kamalakar, G.; Komura, K.; Sugi, Y. Tungstophosphoric acid supported on MCM-41 mesoporous silicate: An efficient catalyst for the di-tert-butylation of cresols with tert-butanol in supercritical carbon dioxide. Appl. Catal. A Gen. 2006, 310, 155-163.

(C) 2013 by the authors; licensee MDPI, Basel, Switzerland. This article is an open access article distributed under the terms and conditions of the Creative Commons Attribution license (http://creativecommons.org/licenses/by/3.0/). 